\title{
Zur Geschichte der Geowissenschaften im Museum für Naturkunde zu Berlin. Teil 3: Von A. G. Werner und R. J. Haïy zu C. S. Weiss - Der Weg von C. S. Weiss zum Direktor des Mineralogischen Museums der Berliner Universität
}

\author{
Günter Hoppe $^{1}$ \\ Mit 5 Textabbildungen
}

\section{Zusammenfassung}

Der Berufung von C. S. Weiss an die Universität Berlin im Jahre 1810 gingen Entwicklungen voraus, die durch die Kristallographie des Franzosen R. J. Haüy, besonders durch dessen Lehrbuch der Mineralogie, ausgelöst wurden. Sie stehen mit der Übersetzung dieses Lehrbuchs im Zusammenhang und führten zur Qualifizierung von C.S. Weiss zum Mineralogen und Kristallographen sowie zur weiteren Entwicklung der Kristallographie innerhalb des Lehrgebäudes der Mineralogie. Den Anstoß gab der mit dem Berliner Mineralogen D. L. G. Karsten befreundete Geologe L. v. Buch, der die Kristallographie Haüys als Erster kennen lernte. Als dessen stark kristallographisch orientiertes Lehrbuch der Mineralogie erschien, entschloss sich Karsten, eine kommentierte Übersetzung desselben zu organisieren. Weiss, der hierfür gewonnen werden konnte, bildete sich zunächst an der Bergakademie Freiberg weiter aus, wobei er die Lehre des führenden Mineralogen A. G. Werner voll in sich aufnahm. Im Verlaufe der Mitarbeit an der Übersetzung gelangte Weiss gegenüber den atomistischen Vorstellungen Haüys zu Ansichten über die Gesetzmäßigkeiten des Kristallbaues, die sich auf Kants Naturphilosophie gründeten. Mit Haüy, den er in Paris näher kennen lernte, kam es deshalb zum Bruch. Seine „dynamische" Kristallographie baute Weiss mathematisch aus und vermochte bereits weit in die Gesetzmäßigkeiten des Kristallbaues einzudringen. Dadurch schuf er die Voraussetzungen für seine Berufung auf den für Karsten vorgesehenen Berliner Mineralogie-Lehrstuhl, der durch dessen frühen Tod frei wurde.

\section{Einleitung}

In den ersten beiden Teilen vorliegender Artikelserie (Hoppe 1998, 1999a) ist die Vorgeschichte der heutigen geowissenschaftlichen Institutionen des Museums für Naturkunde der HumboldtUniversität dargestellt worden. Dies waren die Geschehnisse bis zur Gründung der Berliner Bergakademie und des Königlichen Mineralienkabinetts des preußischen Berg- und Hüttenwesens, ihre Weiterentwicklung und ihre Einverleibung in die Berliner Universität bei deren Gründung im Jahre 1810. Am Ende dieser Periode ereignete sich während der Universitätsgründung der Tod des Mineralogen der Bergakademie und Leiters des preußischen Bergwesens Dietrich Ludwig Gustav Karsten. Als sein Nachfolger an der Berliner Universität wurde der Leipziger Professor der Physik Christian Samuel Weiss im Alter von 30 Jahren berufen, der danach 46 Jahre lang, bis an sein Lebensende, Pro- fessor der Mineralogie und Direktor des Mineralogischen Museums bleiben sollte.

Der vorliegende 3. Teil der Artikelserie ist eine Ergänzung des 2. Teils (Hoppe 1999a) und stellt den besonderen Werdegang von Weiss dar. Seine Entwicklung vom Physiker zum Mineralogen und Kristallographen war eng mit der Berliner Mineralogie verknüpft, worauf im 2 . Teil nur kurz hingewiesen werden konnte. Sie bedarf einer besonderen, weiter ausgreifenden Darstellung, die hier vorgelegt wird. Dabei werden die Umstände in den Vordergrund gestellt, die den Entwicklungsprozess angeregt, begleitet und gefördert haben. Auf eine genaue Darlegung der von Weiss erzielten theoretischen Fortschritte der Kristallographie wird dagegen bewusst verzichtet. Über sie gibt es etliche bedeutende Darstellungen (Schuster 1922, Groth 1925, 1926, Fischer 1962, 1963 , Fabian 1986 u.a.), auf die verwiesen werden kann. Die hier zu behandelnden begleitenden Umstände werden dort nicht oder nur zum Teil berührt.

\footnotetext{
${ }^{1}$ Prof. emer. Dr. Günter Hoppe, Wilhelm-Wolff-Str. 65, D-13156 Berlin; - Museum für Naturkunde, Institut für Mineralogie, Invalidenstr. 43, D-10115 Berlin, Germany. Erhalten November 1999, angenommen Februar 2000
} 
Ein vorgesehener, künftiger 4. Teil der vorliegenden Artikelserie soll die Behandlung der Geschichte der Geowissenschaften an der Universität Berlin von 1810 bis 1856 weiterführen.

\section{Leopold von Buchs Anstoß zur Beachtung von R. J. Haiiys Kristallographie}

In den letzten Jahrzehnten des 18. Jahrhunderts vollzog sich die Entwicklung der Mineralogie vor allem durch Abraham Gottlob Werner (17491817) an der Bergakademie in Freiberg (Sachsen). Letzterer hatte sie zu hoher Perfektion gebracht und zugleich den praktischen Bedürfnissen im Berg- und Hüttenwesen angepasst. Seine Lehre, die alle Teile der damaligen Mineralogie einschließlich der Geognosie (Geologie) umfasste, hatte sich durch seine zahlreichen Schüler in Europa verbreitet und war vor allem in Deutschland führend. Der von Werner besonders gepflegte Teil war die Oryktognosie (Mineralogie im engeren Sinn), die er auf einer gut durchgebildeten und systematisierten Methode der Mineralbeschreibung und -erkennung aufgebaut hatte, für die alle diejenigen Mineraleigenschaften (die sog. äußerlichen Kennzeichen) genutzt wurden, die ausschließlich durch die menschli-

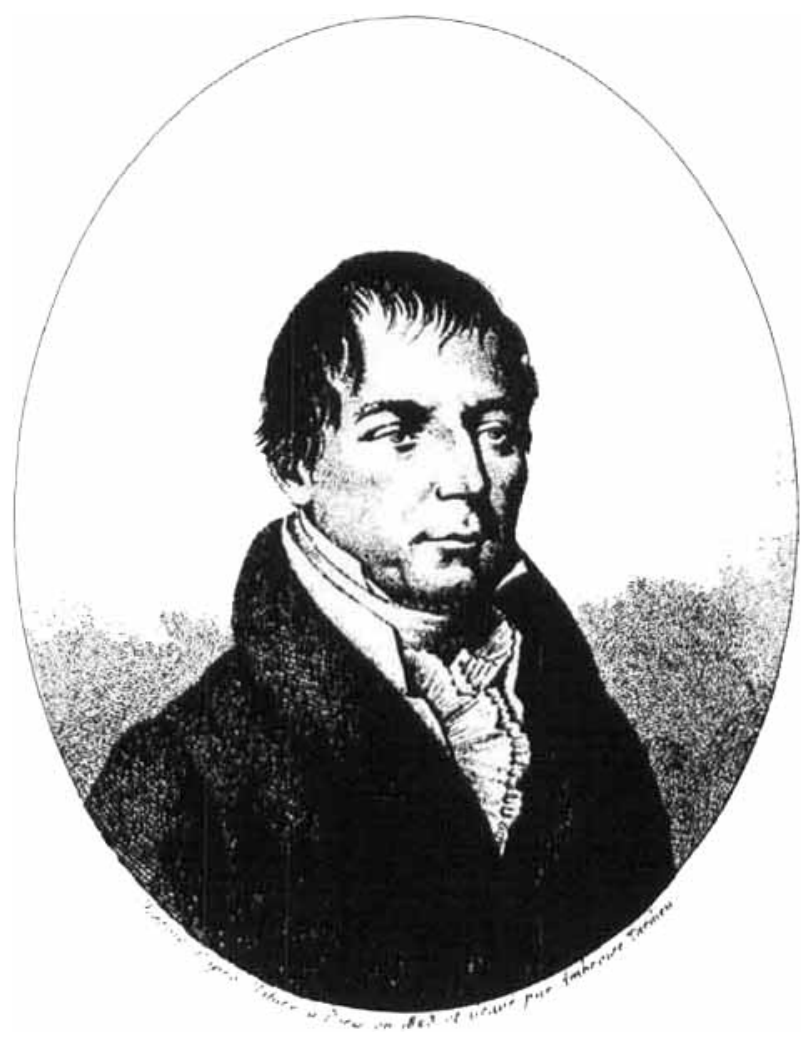

Abb. 1. Leopold von Buch (1774-1853). - Kupferstich in Punktiermanier von Ambroise Tardieu 1823. reproduziert aus Dictionaire d'histoire naturelle, 1830 chen Sinne ohne weitere Hilfsmittel erkennbar und unterscheidbar waren (Werner 1774).

In das große Spektrum der äußerlichen Kennzeichen gehört auch die Kristallgestalt der Minerale. Letztere erfasste Werner rein beschreibend, wodurch jedoch immerhin eine für seine Zwecke ausreichende Vorstellung der Form vermittelt wurde. In seinem Jugendwerk (Werner 1774: 164-197) unterschied er einige Grundgestalten und zwar Zwanzigeck, Achteck, Säule, Pyramide, Tafel und Keil, und zusätzlich gegebenenfalls abgeleitete Flächen, entsprechend einer Abstumpfung. Zuschärfung oder Zuspitzung der Hauptgestalt. Da Werner seinem Buch keinerlei Abbildungen beigab, verwies er auf die Kristallzeichnungen in Carl von Linnés Werk Systema naturae (Linné 1768). Ein genaueres Eingehen auf die Kristallgestalten war für ihn ,vorjetzt ein zu weites Feld" (Werner 1774: 165). Aber auch später hat er es nicht bearbeitet, obwohl er sich um genauere Wortwahl (Werner / Carrozzi 1962) bemüht hat. Festzuhalten ist, dass Werner den Kristallformen keinen Vorrang hinsichtlich ihrer Bedeutung und Verwendbarkeit in seiner Methode gegenüber den anderen äußeren Kennzeichen beimaß.

Dies ist der Hintergrund, vor dem eine Veröffentlichung betrachtet werden muss, die der Wernerschüler Leopold von Buch (Abb. 1) über die Kristallgestalt des Minerals Kreuzstein (Harmotom) von St. Andreasberg im Harz während seines Studiums an der Universität Halle, wohin er nach seiner Ausbildung an der Bergakademie Freiberg gegangen war, erarbeitet und herausgebracht hat (v. Buch 1794). Auf den Kristallund Bruchflächen dieses Minerals, das häufig in Durchkreuzungszwillingen auftritt, beobachtete v. Buch sehr feine Streifungen. Hieraus leitete er die Vorstellung ab, dass die Kristalle aus kleinsten gleichgeformten Bauteilchen zusammengesetzt sind. Er vermutete einen gleichartigen Aufbau auch bei anderen Mineralen, wie Kalkspat, wodurch die Kristallformen ,auf viel einfachere Erscheinungen zurückgestimmt und mehr Verbindung unter die mannigfaltigen Kristallformen gebracht werden“. Er fügte noch an: ,Auch hierin hat uns die Wernersche Kristallographie die Bahn sehr glücklich eröffnet." Dies ist wohl ein Verweis auf Werners Annahme, dass die Gestalt der regelmäßigen Bruchstücke von Mineralen mit blättrigem Bruch, wie Bleiglanz und Kalkspat, von der Gestalt der ,kleinsten zusammengehäuften Teile“ herrührt (Werner 1774: 230).

Wichtig ist nun, dass v. Buch in diesem Artikel ergänzend erwähnte, er habe aus der Literatur 
einen Hinweis auf eine Theorie bekommen, die auf der Vorstellung von kleinsten gleichgestalteten Teilchen in Kristallen basiert. Es war R. J. Haüys Werk „Essai d'une théorie sur la structure des cristaux" (Haüy 1783), das v. Buch aber trotz aller Bemühungen nicht zu Gesicht zu bekommen hat, da es „überhaupt in Deutschland ziemlich unbekannt zu sein scheint." Hiernach scheint Werner, als v. Buch von 1790 bis 1793 bei ihm hörte, Haüy in seinen Vorlesungen nicht erwähnt zu haben.

Den Hinweis auf Haüy hat v. Buch dem Buch des englischen Autors Joseph Townsend (1791) entnommen, worin die von ihm 1786 unternommene Reise nach Spanien beschrieben ist. Sie führte auch über Paris, wo Townsend unter anderem die Sammlungen einiger Wissenschaftler besuchte. Als besonderes Erlebnis beschreibt er einen Besuch bei Haüy. Vor seinen Augen zerlegte Haüy ein ungestaltetes Stück Flussspat und präparierte daraus durch mehrfaches Spalten mittels eines stumpfen Messers einen oktaederförmigen Körper. Townsend berichtete weiter, was ihm Haüy alles über Spaltkörper zahlreicher anderer Minerale mitgeteilt hat, z.B. über die stets gleichen Spaltkörper von Kalkspäten der verschiedensten äußeren Formen nebst den daraus gezogenen Schlussfolgerungen, d.h. über die den Kern der Kristalle bildenden Primitiv- oder Elementarkörper. Hierdurch gelangte Townsend auch zum Verständnis der sinnreichen Beobachtungen von J. B. L. Romé de l'Isle, den er ebenfalls in Paris besucht und vieles von ihm über einfache und zusammengesetzte Formen von Kristallen erfahren hatte. Darüber hinaus sagte ihm dieser noch, dass man die Minerale unfehlbar nach drei messbaren Eigenschaften unterscheiden könne, nach ihrer Form, ihrer Härte und ihrem spezifischen Gewicht.

Als Folgerung aus den Ausführungen Townsends findet man in v. Buchs Artikel über den Kreuzstein nur die Äußerung: „Ich vermute jedoch, dass er [Haüy] sich nur auf die Fossilien ${ }^{2}$ von blättrigem Bruch eingeschränkt habe, die in regelmäßige Bruchstücke springen. Auch schon bei diesen musste die weitere Ausführung solcher Untersuchungen und Beobachtungen lehrreich und wichtig sein“. Über Romé de l'Isle steht in v. Buchs Artikel nichts. Der Grund für diese Unterlassung dürfte gewesen sein, dass die Aussagen Romé de l'Isles ihm als Wernerschüler unglaubwürdig erscheinen mussten, da sie den Ansichten Werners widersprachen, hatte doch vor Jahren der Wernerschüler D. L. G. Karsten, der damals als jugendlicher Bergeleve in Freiberg war, den von ihm übersetzten Artikel Romé de l'Isles über die Identifizierung der Minerale anhand der drei messbaren Kennzeichen (Romé de l'Isle 1784) unter den Augen Werners scharf verurteilt (Karsten 1786). Die Ansichten Haüys dagegen waren in Freiberg offenbar noch gar nicht bekannt oder wurden nicht erwähnt und erschienen deshalb v. Buch als neu und mitteilungswürdig. Hierauf weisen auch folgende Worte v. Buchs in seinem Brief an Werner vom 25.2. 1795 (SBAF-3; Hoppe 1999c) hin, mit denen er seine Sendung des Kreuzsteinartikels begleitete:

„Der Druck des kleinen Aufsatzes, der eigentlich gar nicht zum Druck bestimmt war, geht darauf hinaus, zu zeigen, daß die Kreuzkristalle aus lauter einzelnen, uns freilich unsichtbaren Kristallen zusammengesetzt sind, die alle gerade dieselbe Figur haben, und ich wünsche, daß es durch diese wenigen Beobachtungen etwas mehr als Hypothese möge geworden sein; [...]. Ich bin deswegen bei diesem Aufsatz sehr ängstlich gewesen, nicht anders, als wenn das der Weg wäre, auf dem ich den Stein der Weisen hätte aufsuchen wollen. In der Tat aber scheint mir der Satz, ,daß alle Kristalle aus kleineren. einfacheren von gleicher Gestalt bestehen', von großer Wichtigkeit für die Kristallographie, aber dem man wohl freilich auch nicht solche allgemeine Ausdehnung geben darf als Buffon und Bergman mit ihren fast hypothetisch angenommenen Prismen und Trichtern ${ }^{3}$. Wenn man andere Kristalle einer mechanischen Zerlegung dieser Art unterwürfe, die bei den Kreuzkristallen fast am leichtesten ist, so scheint mir das nichts anderes zu sein, als die Bahn zu verfolgen, die Sie durch die mühsame Aufsuchung der Übergänge der Kristallisationen zuerst betreten und so weit verfolgt haben. [...]"

Entgegen seiner Ankündigung ließ v. Buch dem Artikel über den Kreuzstein von St. Andreasberg keine weitere Publikation über ein kristallographisches Problem folgen. Er motivierte dies damit, dass, wie er am 7.3.1795 an Karsten schrieb (Schuster \& Bloch 1924), die Beobachtungen an den sehr feinen Kristallen seine $\mathrm{Au}$ gen zu sehr angriffen. Jedoch bewahrte er das Interesse an der Kristallographie auch weiterhin, wie sich zeigen wird.

Im Verlaufe seiner ersten großen geologischen Studienreise, die v. Buch von 1797 bis 1799 un-

\footnotetext{
${ }^{2}$ Hier bedeutet Fossilien noch soviel wie Minerale, eigentlich Ergrabenes. Die Bedeutung Versteinerungen kam erst viel später auf.

3 Die Annahmen stammten von dem Franzosen G. L. L. de Buffon (1707-1788) in seinem mehrfach aufgelegten und übersetzten 36bändigen Werk von 1749/88 „Histoire naturelle, générale et particulière“ (in der Übersetzung von Schaltenbrand 1840,2 . Bd., S. 323, ist von Stäubchen die Rede), und von dem Schweden Torbern Bergman (1735-1784) in seiner Abhandlung „De formis crystallorum“ (Bergman 1780).
} 
ternehmen konnte und die ihn von Schlesien aus. wo er Gutachten für das preußische Ministerium für Berg- und Hüttenwesen erarbeitet hatte, nach Wien. Salzburg. Rom und Neapel führte (Hoppe 1999b). kam er im Sommer 1799 auch noch nach Paris. Dort versäumte er nicht, Haüy aufzusuchen. was für ihn sehr wichtig wurde, so dass er darüber später in einem Brief an den Kammerdirektor Karl Maria Ehrenbert v. Moll (1760-1838) in Salzburg. wo er zuvor den Winter $1797 / 8$ verbracht hatte, ausführlich berichtete. Letzterer rückte den Brief in seine Zeitschrift wie folgt ein (v. Buch 1800):

..Ich habe in Paris Haüy genau kennen gelernt. Er hat mich mit Güte und Freundschaft überhäuft. Er ist einer der liebenswürdigsten alten Männer. die man sehen kann, von einer Bescheidenheit. wie sie bei seinen Verdiensten gewiß selten ist. Sein krystallographisches System oder vielmehr seine Krystall-Analysis ist gewiß eine der wichtigsten und merkwürdigsten Erscheinungen dieses Jahrhunderts. In Deutschland kennt man nur einzelne Bruchstucke und ist daher wenig imstande. das Ganze zu übersehen. Haüy hat einen sehr weitläufigen Traité de Minćralogie. vortrefflich ausgearbeitet. ganz vollendet vor sich liegen. von welchem der erste Teil die ganze Methode seiner Analyse umfalit $t^{+}$. Das Werk ist bis jetzt nicht erschienen. weil die Regierung versprochen hat. den Druck zu übernehmen. jetzt aber bei den sich so schnell folgenden Staatsveränderungen die Fonds dazu nicht gefunden werden können. [...]. Diese Haüv'schen KristallisationsEntdeckungen sind nicht bloß interessant für Mineralogie: sie sind eine äuBerst wichtige und höchst sonderbare Erscheinung in der ganzen Körperwelt überhaupt. Alle Körper sind im Stande zu krystallisiren. wenn ihren Theilen dic Bewegbarkeit unter sich entgeht. das heißt. wenn sie rigide [starr. fest] werden. Dies ist ein Satz. der jetzt hinlänglich erwiesen zu sein scheint. Haüy beweist aber. daß. sobald ein Körper aus flüssigem in festen Zustand übergeht. seine aus der Flüssigkeit hervortretenden Theile genau einerlei Form annehmen. und ihre verschiedenen Krystallisationen nur aus der verschiedenen Anhäufung dieser forme primitive entstehen. die sich aus dieser zum voraus berechnen lassen. [...] Ich würde daher die Erscheinung des Haüy schen Werkes für eine Epoche in der ganzen Geschichte der Physik halten $[\ldots]^{-}$

In diesem Brief erwähnt v. Buch noch. dass er sogleich nach der Rückkehr von seiner Reise Karsten im Berliner Königlichen Mineralienkabinett aufgesucht und Minerale von Haüy gezeigt habe. Karsten fand dabei für eines dieser Minerale einen treffenderen Namen als Haüy. "Zweifellos hat v. Buch, der mit Karsten seit 1789 be- kannt war (Ewald 1867), eingehend über seinen Besuch bei Haüy berichtet. Auf ihre persönliche Bekanntschaft hatte sich v. Buch auch im Begleitbrief der Übersendung seiner Kreuzsteinarbeit vom 7. März 1795 (Schuster \& Bloch 1924) bezogen. Vor allem verband sie aber, dass sie beide Schüler von Werner waren, Karsten von 1783 bis 1786, v. Buch von 1790 bis 1793 .

Inzwischen, noch während v. Buchs Reise, war Karsten bereits zum Oberbergrat aufgestiegen und es stand in Berlin auch kurz vor der Erbauung des „Neue Münze“ genannten Gebäudes, in dem - außer den Werkstätten des Münzamtes das Königliche Mineralienkabinett nebst Bergakademie eine museumsartige Unterbringung erhielt (Hoppe 1987). L. v. Buch hielt sich nun abwechselnd in Berlin und in seinem Geburtsort Stolpe an der Oder auf. Die freundschaftlichen Beziehungen zwischen ihm und Karsten entwickelten sich schnell weiter. Karsten führte ihn in die Berliner Gesellschaft naturforschender Freunde ein. ${ }^{6}$ Bald danach verließ $\beta$ v. Buch Berlin für $3 \frac{1}{2}$ Jahre und ging im Auftrage des preuBischen Ministeriums für Berg- und Hüttenwesen zu geologischen Untersuchungen der Bodenschätze in das damalige preußische Fürstentum Neuchâtel (Neuenburg) in der Schweiz. Die lange Abwesenheit unterbrach die Beziehungen zu Karsten aber keineswegs. Vielmehr hielt Karsten den Kontakt v. Buchs zur Gesellschaft naturforschender Freunde durch Verlesen von dessen Briefen und Aufsätzen aufrecht, wie man aus den Tagebüchern der Gesellschaft (HHMfN-1) entnehmen kann. Noch deutlicher wird das gegenseitige Verhältnis durch die erhalten gebliebenen Briefe v. Buchs an Karsten (Schuster \& Bloch 1924), in denen der Name Haüy und das Thema Kristallographie auftauchten, wenn auch mit längerer Pause während des Aufenthaltes v. Buchs in Neuchâtel. Dies änderte sich erst, als v. Buch im Jahre 1804 die Aussprache mit seinem alten Lehrer suchte, um das durch seine Forschungsergebnisse zum Thema Basalt und Vulkane belastete Verhältnis zu bereinigen, bei der

\footnotetext{
${ }^{4}$ Zu diesem Manuskript des Traité de Minéralogie (Lehrbuch der Mineralogie) hat v. Buch dadurch beigetragen, dass er bei seinem mehrmonatigen Aufenthalt in Paris die deutschen Namen aller im Buch behandelten Minerale nach der Nomenklatur Werners bestimmte und benannte. was Haüy im 1801 erschienenen Lehrbuch ausdrücklich anerkannt hat (Haüy 1801. Bd. 1. S. LIII). Wie Haüy schrieb. war dadurch die für ihn ..größte Schwierigkeit” bei der Angabe der Synonyma behoben worden.

Es war ein Mineral aus der Bretagne. dem Haüy die vorläufigen Bezeichnung .macle“ gegeben hatte. Zu diesem Mineral kannte Karsten ein gleiches aus dem Fichtelgebirge und schlug vor. dem Mineral nach der auf dem Querbruch zu erkennenden kreuzförmigen Pigmenticrung. die dem griechischen Buchstaben Chi $[\gamma]$ gleicht. mịt ..Chiastolith“ einen günstigeren Namen zu geben.

Karsten gehörte zu den maximal 12 ordentlichen Mitgliedern. die sich in den Dircktorgeschäften turnusmäßig abwechselten. Die Gesellschaft nahm auch weitere. auswärtige oder Ehren-Mitglieder auf, wofür Karsten v. Buch vorschlug (HHMfN-1)
} 
dann auch Haüys Kristallographie zur Sprache kommt. Bevor hierauf eingegangen wird, muss zunächst noch eine andere Entwicklung betrachtet werden.

\section{L. G. Karsten als Organisator der Übersetzung des Lehrbuchs der Mineralogie von R. J. Haüy}

Als Haüys „Traité de Minéralogie“ (Haüy 1801) erschienen war und nach Berlin gelangte, überzeugte sich Karsten vom Wert dieses Werkes, auf das er bereits durch v. Buch vorbereitet war. Im April und Mai 1802 hielt er darüber in Berlin Vorträge, sowohl vor der Philomathischen Gesellschaft ${ }^{7}$ als auch vor der Gesellschaft naturforschender Freunde. In den Tagebüchern letzterer Gesellschaft (HHMfN-1) findet sich am 4. 5. 1802 folgende Notiz: „Karsten las einen Aufsatz über die neue Methode der Kristallographie des H. Haüy in Paris vor, wobey er Modelle und natürliche Körper vorzeigte und erklärte, sowohl nach ihren primitiven als sekundären Formen. Er wird diesen Aufsatz in Hoffs Magazin für die Mineralogie abdrucken lassen." Hierzu kam es jedoch nicht, da die von Karl Ernst v. Hoff herausgegebene Zeitschrift, das „Magazin für die gesamte Mineralogie, Geognosie und mineralogische Erdbeschreibung", bereits nach 4 Heften des ersten Jahrgangs 1801 noch im gleichen Jahre einging. Das Manuskript ist erhalten geblieben. ${ }^{8}$ Im Folgenden wird dieser Vortrag etwas gekürzt wiedergegeben. Karsten informiert darin über die Geschichte und über den von Haüy erzielten Stand der Kristallographie.

\section{Über Herrn Haïys Methode der Kristallographie (Von D. L. G. Karsten)}

Mehreren Mitgliedern der Philomathischen Gesellschaft habe ich vor einiger Zeit versprochen, ihnen, sobald die Reihe der Vorlesung mich treffen würde, eine Idee von der kristallographischen Methode des Herrn Haüy in Paris zu geben, welche in Frankreich mit außerordentlichem Beifall aufgenommen ist, in England bereits kultiviert wird, von den deutschen Mineralogen aber, wie es scheint, noch wenig gckannt ist. $[\ldots]^{9}$

Chemiker und Physiker kannten und ehrten das Wort Kristallisation, aber die Kristalle kannten sie nicht. Jene erzeugten sie täglich in ihren Laboratorien, sie hatten aber die Konstruktion derselben nicht beachtet und ihre Beschreibungen der Formen blieben nur allzu lange höchst mangelhaft. Obwohl man sich unter einem Kristall einen Körper dachte. der den regelmäßigen geometrischen Körpern ähnlich wäre. so drang man doch nicht tiefer in ihre Natur ein, daher eine Kristalldruse oft als ein chaotischer Klumpen von bloß regulär scheinenden Körpern angesehen ward. [... ${ }^{10}$

Dies hat sich gegenwärtig geändert. Alle Zweige der gesamten Naturgeschichte sind einander näher gerückt und die Naturkunde wird in allen ihren Teilen aus einem umfassenden Gesichtspunkt betrachtet. [...] Die Lehren von den Kristallformen erhalten daher ein allgemeineres Interesse und es werden sich künftig umso weniger die Mineralogen allein damit beschäftigen dürfen, wenn die großen Fortschritte, welche die Kristallographie seit Haüys Bearbeitung derselben erfahren hat, wirklich zur Entdeckung von ganz eignen, bisher nicht geahndeten Naturgesetzen fuihren sollte, wozu aller Anschein vorhanden ist. Um aber das Eigentümliche seiner Methode in kurzem darstellen zu können, muß ich einen Augenblick auf die Geschichte der Kristallographie im vorigen Jahrhundert zurückgehen.

Linné unterwarf die Kristalle einer sorgfältigeren Betrachtung im 3. Teil seines Systema naturae. Er wähnte in jedem Kristall des Steinreichs ein Salz, nämlich dasjenige, dessen regelmäßige Form er in jenem antraf, daher Nitrum - Crystallus Montana Natrum glaziale ${ }^{11}$ etc. Das Salz schien ihm eine Art Befruchtungsmaterie, wodurch die Steine die Form des ersten [Salzes] erhielten, und so glaubte er im Mineralreich die Grundzüge des Sexualsystems wieder zu finden, welches er bei den organisierten Körpern so sinnreich als glücklich angewendet hatte. [...]

Romé de 1'Isle führte eine größere Genauigkeit bei Betrachtung und Behandlung der Kristalle ein, stellte diejenigen zusammen, welche ihrer Natur nach miteinander übereinkommen, suchte gewisse Grundgestalten nach dem Gesetz der Einfachheit auf, führte auf diese Weise seit 1772 [Romé de l'Isle 1772] eine eigene Disziplin unter dem Namen der Kristallographie ein und bereicherte bis zum Jahre 1783, als die 2. Auflage seines Werkes in 4 Textbänden nebst Atlas erschien [Romé de l'Isle 1783], durch eine große Summe von Beobachtungen diesen Teil der Oryktognosie ungemein. Seine damaligen Grundkörper waren: Tetraeder, Würfel, rautenförmiges Parallelepipedon und rechtwinkliges Oktaeder. - Er leitete durch Abstumpfungen und Zuschärfungen hiervon die übrigen Gestalten her, maß die hauptsächlichsten Winkel, brachte die Resultate in großen Tabellen und war der erste, welcher die Behauptung darlegte, daß die Winkel bei jeder Unterart beständig wären.

Werner, der im Jahre 1774 seine Abhandlung von den äußerlichen Kennzeichen der Fossilien herausgab und da-

\footnotetext{
${ }^{7}$ Die Philomathische Gesellschaft bestand erst seit 2 Jahren. Sie war von Klaproth, ihrem ersten Direktor, ins Leben gerufen worden (Biester 1804). Ihr Name sollte die Liebe zu allem Wissenswerten bedeuten und zugleich auch auf eine größere Breite ihres Interessengebietes hinweisen.

${ }^{8}$ Das Manuskript befindet sich in der Handschriftenabteilung der Universitätsbibliothek Bonn (HUBB-1). Es umfasst 12 Seiten, ist von fremder Hand geschrieben und enthält die eigenhändige Unterschrift Karstens nebst wenigen, von ihm vorgenommenen Textverbesserungen. - Für die Gestattung des Abdruck des Textes wird Frau C. Weidlich freundlichst gedankt.

${ }^{9}$ Karsten führt zunächst aus, dass außer Mineralogen nur einige Mathematiker sich mit Kristallen beschäftigt haben und nennt den Pariser Philippe de La Hire (1640-1718) und den Göttinger Abraham Gotthelf Kästner (1719-1800) sowie das Buch von C. Bekkerhin und C. Kramp (1793).

${ }^{10}$ Karsten geht weiterhin auf die Gegenüberstellung von organischen und unorganischen Naturkörpern in der Literatur ein, wodurch aber kein Interesse für die Kristalle entstanden sei.

11 Crystallus Montana = Bergkristall (Quarz) wurde von Linné dem Nitrum = Salpeter wegen der (vermeintlichen) gleichen äußeren Form zugeordnet.
} 
durch die Oryktognosie völlig reformierte. behandelte darin dic Lehre von den Kristallisationen auf eine ähnliche. in mancher Hinsicht aber noch populärere Weise als Romé de l'Isle. Er bediente sich aber des Winkelmessers gar nicht. weil er von dem Gesichtspunkt ausging. man müsse bloß seine Sinne zu Hilfe nehmen und könne zur Untersuchung der Fossilien ${ }^{12}$ Gerätschaften entbehren. Werner blieb daher ebenteils dabei stehen. Grundgestalten nach dem Gesetz der Einfachheit aufzufinden. ihre eigenen Verschiedenheiten aufzufinden und aus der Abstumpfung. Zuschärfung und $\mathrm{Zu}$ spitzung diejenigen Formen zu erklären. welche außer den Flächen der Grundgestalt noch andere Flächen zeigen. deren Gegenwart zuweilen die Bestimmung der ersteren nicht wenig erschwert.

Die von Werner angenommenen Grundgestalten sind: Ikosaeder. Dodekaeder: Linse. Würfel. Säule. Pỳramide und Tafel. ${ }^{13}$ Abweichungen in ihren Winkeln. in dem Verhältnis der Stellung und Anzahl ihrer Flächen (letzteres aber nur bei der Säule. Tafel und Pyramide) geben die Verschiedenheiten. Veränderungen der Grundgestalten schränkt er bloß auf diejenigen Modifikationen ein. welche durch neu hinzutretende Flächen (Veränderungsflächen). nämlich durch Abstumpfungen. Zuschärfung und Zuspitzung ${ }^{1+}$ anscheinend entstehen. Auch hat Werner in sehr mannigfaltig vorkommenden Abweichungen und Abänderungen die Grundgestalt höchst sorgfältig gesammelt und bezeichnet. hat sodann bekanntlich noch nähere Bestimmungen in Rücksicht der Größe und des Zusammenhangs der Kristalle hinzugefügt und dadurch bewirkt. daß man danach ein sehr anschauliches und vollständiges Bild von gegebenen Kristallisationen für diejenigen entwerfen kann. welche mit seiner Methode gehörig vertraut sind. Dieser Methode sind daher Wiedemann [Widenmann] (mit Hinzufügung des Oktaeders als Grundgestalt). Emmerling. Estner, Wad. Struve und Brochant gefolgt ${ }^{15}$. auch ich habe sie in meinen mineralogischen Tabellen [Karsten 1791/ 92] zugrunde gelegt.

Der in den mathematischen Wissenschaften sehr geübte. verstorbene Chemist Bergman in Schweden ${ }^{16}$ war der Zeitfolge nach der erste. welcher bis in die innere Struktur der Kristalle eindrang. Er betrachtete die verschiedenen. ein und derselben Substanz angehörigen Formen als Produkte der Auftürmung von Flächen (die sich teils gleich bleiben. teils in der Größe verändern) von und über einer Grundgestalt. Die Bestätigung dieser Idee fand er in einer Kalkspat-Abänderung (der doppelt sechsseitigen Pyramide). aus welcher es ihm gelang. die rhomboidisch primitive Form darzustellen. Die hierbei angestellten Beobachtungen wandte er auf Schörlund Granatkristalle. wie auch auf die übrigen Kristallabänderungen von Kalkspat an. Hierbei blieb er stehen und verfehlte selbst in Absicht auf die bewirkte Enthillung des Kalkspatkerns das wahre Resultat. Man sehe seine Abhandlung ...De formis crystallorum“. Upsala $1780 .^{17}$

Was in Frankreich der Abbé Haüy (Abb. 2) um dieselbe Zeit in gleicher Art ahnte. trug dieser Gelehrte schon weit

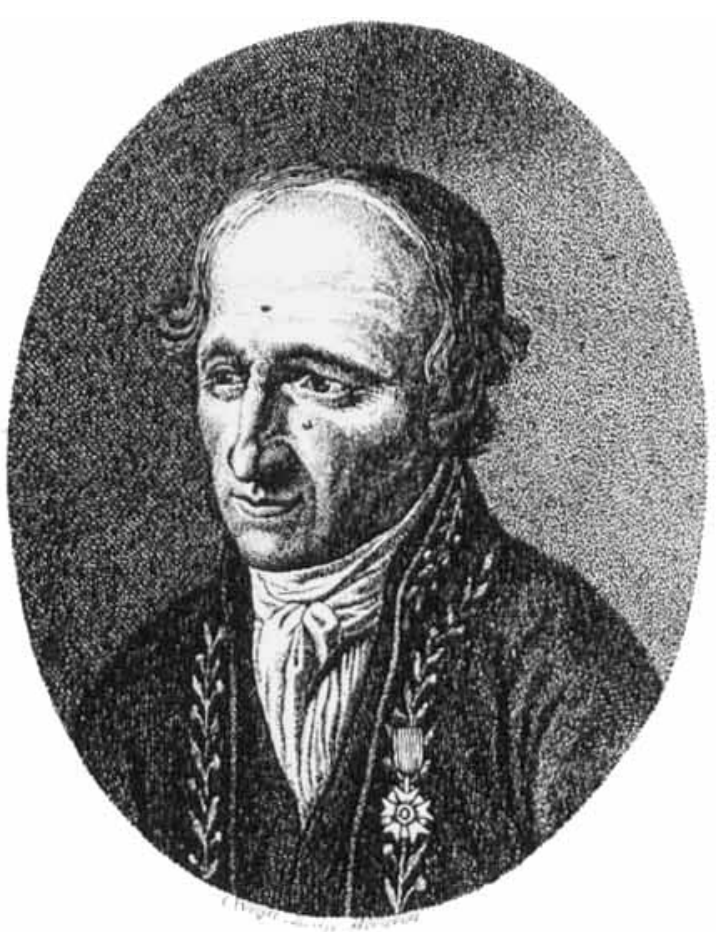

Abb. 2. Renć Just Haüy (1743-1822). - Kupferstich in Punktiermanier von C. Westermayr, reproduziert aus Taschenbuch für die gesamte Mineralogie, Hrsg. C. C. Leonhard. 3 (1809)

umständlicher vor. in dem „Essai d'une théorie sur la structure des cristaux". Paris. [Haüy 1783]. Aber die lichtvollste Entwicklung einer der sinnreichsten und, wie es scheint, fruchtbarsten Vorstellungsarten uber die Natur der Kristalle blieb dem ersten Jahre unseres angetretenen Säkulums vorbehalten. Sie findet sich in Haüys vierbändigem "Traité de minéralogie" mil 86 Kupferplatten in einem zusätzlichen (Folio-) Band. Paris. [Haüy 1801].

Die Hauptzüge der Theorie Haüys sind folgende:

1. Die meisten von der Natur vollendeten Kristallisationen sind sekundäre Gestalten.

2. Die primitiven Gestalten können nicht willkürlich angenommen. sondern nur durch mechanische Zerlegung oder durch Berechnung der Kristalle aufgefunden werden. Die Zerlegung ist parallel mit dem Durchgang der Blätter ${ }^{\text {ss }}$ vorzunehmen.

3. Dieses führt auf einen Kern, der sich in allen noch so verschiedenen Formen, sofern solche ein und derselben Gattung ${ }^{\text {ly }}$ zukommen, gleich bleibt.

\footnotetext{
12 Vgl. Anm. 1

13. Gegenüber der ursprünglichen Aussage (Werner 1774) waren die Grundgestalten inzwischen von Werner in seinen Vorlesungen etwas verändert worden.

${ }_{14}$ (Fußnote von Karsten): Die Idee einer Zuspitzung lag zwar auch in der Behandlung. welche Romé de l'Isle bei der Bearbeitung seiner Kristallographie zu Grunde legte. aber nur unvollkommen. Herr Werner führte diesen Ausdruck erst ein und lehrte seine Anwendung auf eine der repräsentativen Methode sehr günstige Weise.

15 Alle genannten Autoren haben Lehrbücher der Mineralogie. die auf der Lehre Werners basierten, veröffentlicht: Widenmann (1794). Emmerling (1793/9). Estner (1794/9). Wad (1798). Struve (1799). Brochant [de Villiers] (1801/3).

16 Torbern Bergman (1735-1784) war Professor der Chemie und Pharmazie an der Universität Uppsala. Er entdeckte bereits 1773. von J. G. Gahn (1745-1818) (Groth 1926: 14) unterstützt. die Grundkörper von Kristallen durch Spaltung und entwickelte die Dekreszenzvorstellung zur Ableitung anderer Kristallformen (Bergman 1773).

Bergman (1780). deutsche Übersetzung von H. Tabor (Bergman 1782).

Karsten verwendet mit den Worten ..Durchgang der Blätter" die Sprache Werners. Hier sind die Spaltebenen des Kristalls. die zum Teil durch Risse äußerlich sichtbar angedeutet sind. gemeint.

19 Eine Gattung bedeutet sovicl wie Mineralart.
} 
4. Der Kern ist die primitive Form (Urgestalt). Ihre Flächen laufen mit der Richtungsebene der Blätter ${ }^{20}$, woraus die Kristalle bestehen, parallel.

5. Die primitive Form läßt sich noch weiter mechanisch analysieren, bei einigen Kristallen gleichlaufend mit den Seiten, bei anderen aber auch nach anderen Richtungen. Das Resultat dieser nochmaligen Teilung liefert die integrierenden Moleküle. ${ }^{21}$

6. Diese bestehen aus elementarischen Molekülen. Dies sind die körperlichen Formen der einzelnen Bestandteile welche die Mischung ${ }^{22}$ des Fossils ausmachen. - Weder unsere Sinne noch unsere Werkzeuge reichen so weit dass wir diese letzteren Gestalten, die elementarischen Moleküle, erkennen oder bestimmt angeben könnten. Indessen ist es wohl nach der Analogie erlaubt, sie vorauszusetzen, zumal durch dieses Resultat, man mag es an nehmen oder verwerfen, die übrigen höchst anziehenden Lehren Haüys keine Veränderung erleiden.

7. Allen bisher bekannt gewordenen Fossilien liegen, un geachtet einer ganzen Welt von Kristallisationen, welche die Kabinette jetzt schon beherbergen, eine der folgenden Grundgestalten zugrunde: a) das Parallelepipedon, u. a. beim Kalkspat, Titanit, Baryt, blättrigen Zeolith und Turmalin; b) das Oktaeder, u. a. beim Flussspat, Chiastolith, Spinell, Galmei, Olivenerz und Bleiglanz; c) das Tetraeder, u. a. beim Kupferkies und Fahlerz; d) das sechsseitige regelmäßige Prisma, u. a. beim Sapphir, Smaragd, Apatit und Sommit; e) das Rhomboidal-Dodekaeder, u. a. beim Almandin und bei der Blende.

8. Es gibt unter den integrierenden Molekülen 3 Formen: a) die 3flächige Pyramide, u. a. beim Turmalin, Augit, Galmei und Leucit; b) das 3flächige Prisma, u. a. beim Apatit und Staurolith; c) das 4 flächige Prisma, u. a. beim Kalkspat, Thallit und Rotgültigerz. Diese Moleküle sind daher die einfachsten regelmäßigen Körper, welche möglich sind.

9. Abweichungen der Winkel oder der Exponenten des Verhältnisses der anderen Dimensionen treten bei gleicher primitiver Form alle Mal da ein, wo verschiedenartige Mischungen yorhanden sind, also bei den verschiedenen Gattungen. Die sekundären Gestalten werden gebildet durch Aufschichtung kleiner Moleküle, die in abnehmenden oder abschüssigen Reihen von der Urgestalt ausgehen ${ }^{23}$, entweder parallel mit den Kanten, parallel mit der Diagonalen oder zwischen beiden Richtungen laufend. Diese Reihen entspringen überdies von mehreren Seiten zugleich oder nur von einer einzigen.

10. Die primitiven Formen der sekundären Gestalten lassen sich auffinden: mechanisch nach der Richtung der innerlichen Blätter bzw. der äußerlichen Streifen ${ }^{24}$ sowie geometrisch durch Messung und Berechnung.

Hauiy stellte als Folge seiner Lehre die Behauptung auf, da 3 der sibirische Smaragd [jetzt Dioptas] kein Smaragd ist, der kristallisierte sogenannte glasige Strahlstein [jetzt Thallit] kein Strahlstein, das würflige Olivenerz kein arseniksaures Kupfer, sondern alle diese Fossilien, auch der vulkanische Schörl [jetzt Sommit], ganz eigene, für sich bestehende Gattungen bilden. Er schlo $\beta$ dies blo $\beta$ aus den vorgefundenen Abweichungen ihrer primitiven Formen. Die hiernächst geschehenen Zergliederungen durch Klaproth und Vauquelin ergaben auch wirklich auffallende Verschiedenheiten in den Bestandteilen der für eigentümlich erklärten Gattungen.
Im umgekehrten Fall lehrte diese Methode gewissermaßen a priori, daß gewisse Fossilien, welche als verschiedene Gattungen betrachtet wurden, in eine einzige zu vereinigen sind. In dergleichen Fällen hat die später vorgenommene Analyse dic Identität in den Mischungen der Bestandteile dargetan. So behauptete Haüy, daß der Hyazinth und der Zirkon, desgleichen der Zirkonit, keine generisch verschiedenen Fossilien wären, daß der Smaragd und Beryll zu einer und derselben Gattung gerechnet werden müßten, daß der Chrysolith der Franzosen (Werners Spargelstein) mit dem sächsischen Apatit, der Kokkolith mit dem Augit übereinkomme. Alle hinterher vorgenommenen Analysen haben auch dieses auf das vortrefflichste bestätigt.

Bei der Beschäftigung mit dem Werk Haüys war Karsten zu dem Entschluss gekommen, es zu übersetzen. Infolge der Inanspruchnahme durch seine Diensttätigkeit wollte er sich jedoch nur auf die Revision einer Übersetzung beschränken, sowie auf die Kommentierung durch Anmerkungen, mit denen er speziell den Werner-Anhängern das Verständnis erleichtern wollte, und suchte nach Übersetzern. Seine Wahl fiel auf zwei junge Wissenschaftler, die sich im Winter 1801/2 gerade in Berlin aufhielten. Es waren sein jüngerer Vetter, Carl Johann Bernhard Karsten (17821853) (Abb. 3), der 1802 in Rostock mit einer chemischen Dissertation promoviert hatte, ${ }^{25}$ und der Leipziger Physiker Christian Samuel Weiss (1780-1856), der in Leipzig sein Studium mit Medizin begonnen und mit einer physikalischen Dissertation 1801 abgeschlossen hatte (Weiss 1801a, Paufler 1981). ${ }^{26}$ Beide willigten ein und es kam noch im Winter zur Verständigung über die $\mathrm{zu}$ beachtenden Grundsätze und über die Aufteilung (Haüy 1804: X). Allerdings erfährt man zunächst nichts darüber, welche Teile konkret von wem übersetzt werden sollten. Auch zog sich der Druck lange hin. Der erste Band erschien 1804, der vierte erst 1810 (Haüy 1804/06/ 10). Weiss hatte schon vom 3 . Band an die Revision übernommen. Das Vorwort des 4. Bandes, das Weiss verfasst hat, verrät endlich die Aufteilung der Übersetzung (Haüy 1810: VII):

„Zufolge der Einteilung, welche wir bei der Übernahme der Übersetzung, die wir damals sehr schnell zu liefern willens waren, unter uns trafen, rührt von mir im 1. Bande die Übersetzung des räsonnierenden Teiles, von Hrn. C. J. B. Karsten die des geometrischen Teiles her. Ich übernahm dann in den folgenden die Übersetzung der Klasse der säurehaltigen Substanzen, er die der erdigen, ich wieder die der

${ }^{20}$ Bei Haüy wird hierfür der Begriff ,joints“ (Fugen) gebraucht, Karsten denkt bei den „Blättern“ auch an räumliche, von Spaltflächen begrenzte Kristallbereiche.

${ }^{21}$ Bei Haüy: molécule intégrante, soviel wie kleinste Kristallbauteilchen.

${ }^{22}$ Mit "Mischung" ist die chemische Zusammensetzung gemeint.

${ }^{23}$ Mit diesen Worten umschreibt Karsten den von Haüy benutzten, erstmals bei Bergman (1773) auftretenden Begriff décroissement (Dekreszenz). Umschreibung in modernerem Deutsch: Wachstum durch jeweilige Auflagerung weniger weit ausgedehnter Schichten.

24 Vorhandene Streifungen auf den Kristallflächen können die Spuren von potentiellen Spaltebenen angeben. 
unmetallischen brennlichen Körper und der Metalle bis zum Arsenik. Hr. Karsten die vom Mangan an bis zum Schiuß3 des Werkes."

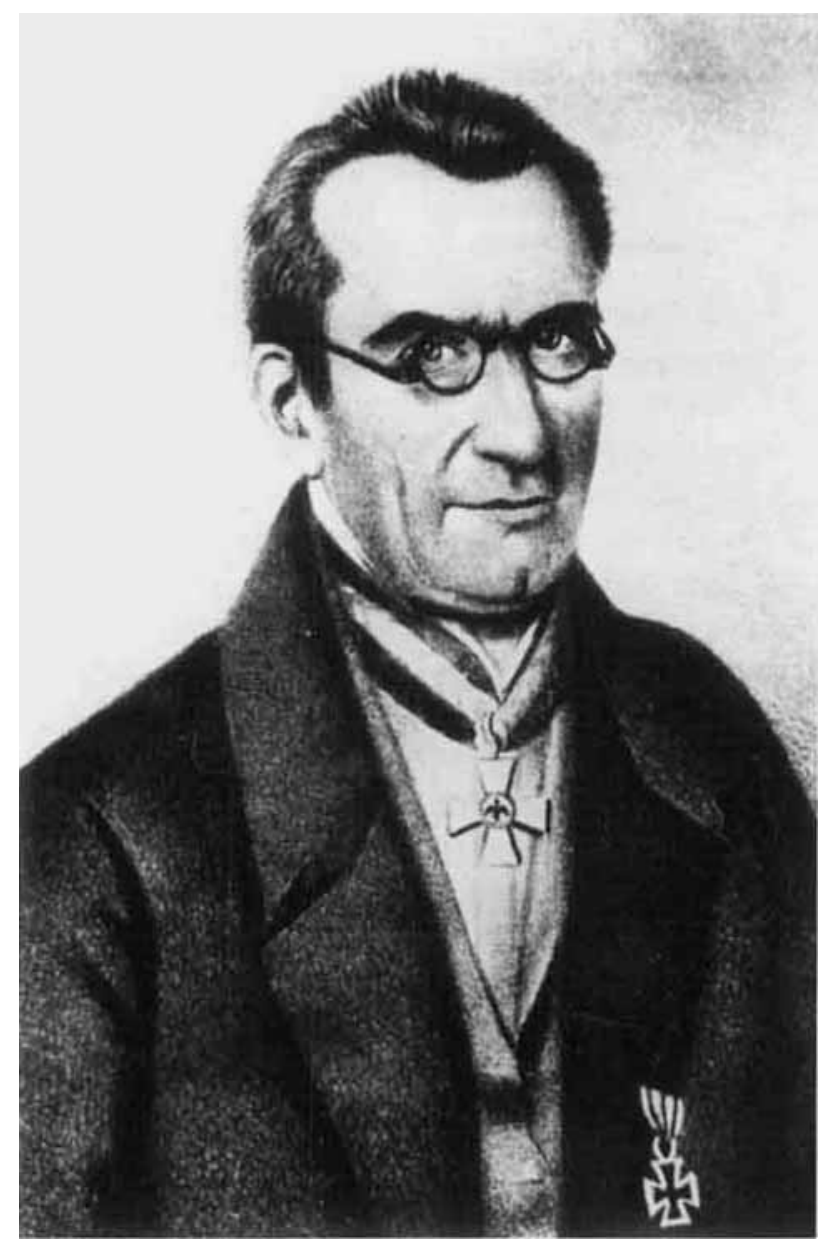

Abb. 3. Carl Johann Bernhard Karsten (1782-1853). der 14 Jahre jüngere Vetter von D. L. G. Karsten. - Reproduziert nach einem im Berliner Museum für Naturkunde vorhandenen Foto eines Portraits. das große Ähnlichkeit mit der 1855 im Archiv für Mineralogie. Geognosie. Bergbau und Hüttenkunde erschienenen. von Engelbach geschaffenen Lithographic besitzt
Dies bedeutet, dass sich die Teile der beiden Übersetzer alternierend über alle Bände verteilten und der Umfang der übersetzten Teile genau gleich groß war. Selbst am 4. Band war C. J. B. Karsten noch beteiligt. Letzterer hat seine übernommene Verpflichtung erfüllt und es trifft nicht zu, dass er, wie in seiner Biographie (G. Karsten 1855) angegeben ist, ,durch die Wendung seiner Laufbahn die Arbeit bald seinem Freunde Weiss ganz überlassen" hat. Im Gegenteil dürfte er weit eher mit seinen Anteilen fertig gewesen sein als Weiss. ${ }^{27}$

\section{S. Weiss als Übersetzer des Lehrbuchs der Mineralogie von R. J. Haüy}

Die Anwesenheit von C. S. Weiss in Berlin geht auf die Beantwortung einer Preisfrage der Gesellschaft naturforschender Freunde zu Berlin zurück. Diese Arbeit über den Anteil der Elektrizität an der Hagelbildung (Weiss 1801b) hatte ihm die Mitgliedschaft dieser Gesellschaft eingebracht, was ihn veranlasste, sich im Oktober 1801 dort einzufinden. Er blieb dann bis zum Mai 1802 in Berlin und besuchte die Vorlesungen, die Martin Heinrich Klaproth im Rahmen der Bergakademie über Chemie hielt, und wohl auch die über Mineralogie von D. L. G. Karsten. Vor der Gesellschaft naturforschender Freunde sprach er am 24.11.1801 über die „Farbentheorie"., was Karsten in der Diskussion mit Fluoreszenzversuchen am Apatit begleitete. Weiss fand sich bei dieser Gesellschaft jede Woche ein, auch der Vetter Karstens und der Däne Hans Christian Oersted. ${ }^{28}$ Mit letzterem entwickelte Weiss eine Freundschaft, die Oersted in einem Brief an seinen Bruder vom 7. 2. 1802 charakterisiert:

${ }^{25}$ Carl Johann Bernhard Karsten war von Mitte 1801 bis Mitte 1802 in Berlin mit Redaktionsarbeiten für Alexander Nicolaus Scherer an dessem Allgemeinen Journal der Chemie beschäftigt (G. Karsten 1855: 224ff.). Von seinem Vetter nachhaltig gefördert. schlug C. J. B. Karsten danach die Hüttenlaufhahn im preußischen Bergwesen ein, in der er sich später große Verdienste im schlesischen Hüttenwesen u.a. durch die Organisation der Zinkgewinnung erwarb. Er machte sich außerdem mit der langjährigen Herausgabe einer Zeitschrift (..Karstens Archiv“. d. h. Archiv für Mineralogie, Geognosie, Bergbau und Hüttenkunde. Berlin. 26 Bände. 1829-1855) einen Namen.

2t Christian Samuel Weiss. der aus einer Leipziger Pfarrerfamilie stammte. hatte 7 Geschwister: Christian (1774-1853), Pädagoge: Christian Benjamin ( $* 1777$ ). Jurist: Fritz (Friedrich) († um 1838) (wurde Vater des Paläontologen Christian Ernst Weiss (1833-1890). d.h. des Neffen von C. S. Weiss): Christian Jakob ( $\left.{ }^{*} 1787\right)$ : Christian Ernst (1787-1852), Jurist; Christian Konrad (*1790): eine Schwester (wurde die Mutter der Jugendschriftstellerin Clementine Helm, die den Berliner Paläontologen $H$. E. Beyrich heiratete).

C. S. Weiss schloss sich bei einem mehrjährigen Schulbesuch in Hirschberg (Schlesien) seinem ältesten Bruder Christian in einem engen Vertrauensverhältnis an. das lebenslang hielt. Über seine Entwicklung und seine Lebensumstände geben die zahlrcichen. umfang- und aufschlussreichen Briefe an diesen Bruder und an andere Geschwister (HASTB-3) ausführliche Auskunft. Sie wurden schon mehrfach benutzt (u.a. von Schuster 1922. Groth 1926. Fischer 1962, Hoppe 1982), aber nicht vollständig veröffentlicht. Auch hier werden sic verwendet. Die meisten Briefe sind an den ältesten Bruder gerichtet.

27 Auch die Angabe von Groth (1926: 59), wonach Weiss den größten Teil der Übersetzung ausgeführt hat, trifft nicht zu.

2* Hans Christian Oersted bildete sich in Berlin bei M. H. Klaproth weiter und war bereits Adjunkt der Physik an der Universität Kopenhagen. 1806 wurde er dort Professor. Seine bedeutende Entdeckung des Elektromagnetismus im Jahre 1820 hatte ihre Wurzeln ebenfalls in der Naturphilosophie. 
„Ich glaube, es wird dich erfreuen, zu hören, daß ich hier in Berlin einen gelehrten Freund gefunden habe. Es ist Dr. Weiss aus Leipzig. [...] Er verbindet mit einem geübten und freien Geist den größten Eifer für die Naturwissenschaften und hat viele glückliche Ideen. Es ist schade, daß er sie nicht prüft durch Experimente."

Die Freundschaft hielt sehr lange, wie ihr Briefwechsel zeigt (Örsted 1920). Bei den täglichen Zusammenkünften Oersteds mit Weiss und C. J. B. Karsten wurde die Naturphilosophie Kants studiert.

In dieser Zeit warb D. L. G. Karsten seinen Vetter und C. S. Weiss für die Übersetzung des Mineralogielehrbuchs von Haüy an. Weiss hatte sich in seiner Dissertation (Weiss 1801a) auf der Basis der Ansichten Kants (1786) und Schellings $(1797,1799)$ mit den Definitionen des flüssigen und des festen Zustandes beschäftigt, war dabei durch den Artikel von v. Buch (1800) auf Haüy aufmerksam geworden und fand an dem Angebot Interesse. Er ging auch darauf ein, sich intensiv in der Mineralogie weiterzubilden. Auf Anraten Karstens und v. Buchs entschloss er sich, zu dem führenden Mineralogen A. G. Werner nach Freiberg zu gehen, und hörte in Berlin als Letztes noch Karstens Vortrag über Haüys Kristallographie in der Gesellschaft naturforschender Freunde am 4.5.1802. Über seinen Aufenthalt in Freiberg ist nur wenig bekannt, da er von dort aus keine Briefe an seine Geschwister geschrieben hat, auch war er nicht in der Freiberger Matrikel eingetragen. ${ }^{29}$ Aus seinem späteren Verhalten geht jedoch hervor, dass er das Studium bei Werner mit großer Aufgeschlossenheit betrieben haben muss. Bereits zu Ostern
1803 kehrte er nach Leipzig zurück und hielt dann dort bis 1805 Vorlesungen in Chemie, Mineralogie, Geognosie und physikalische Wissenschaften (Kreußler 1810: 73, Paufler 1981: 429).

Während des Freiberger Aufenthaltes von Weiss unternahm Werner eine Reise nach Paris, von der er Mitte Dezember 1802 zurückkehrte. Bisher war über diese Reise nur wenig bekannt, durch eine Publikation aus dem Nachlass von P. Schmidt $\uparrow$ (1999) ergibt sich, dass die Reise 4 Monate dauerte und vom 14. Juli 1802 an über Aachen und Ostende nach Paris führte, sowie dass das Tagebuch der Reise verschollen ist. ${ }^{30}$ Was den Anlass zu dieser Reise betrifft, liegt es wohl nahe, dass Werner durch Mitteilungen über Haüy, die ihn aus der Literatur oder über Schüler, wie v. Buch oder Weiss erreichten, zu dieser Reise bewogen wurde. ${ }^{31}$ In Paris traf Werner jedenfalls unter anderem mit Haüy zusammen und erfuhr wegen seiner Fähigkeit, Minerale schnell und sicher zu erkennen, hohe Anerkennung. Es erregte auch Erstaunen, dass Werner in der Lage war, die Metallgehalte von Erzen nach ihrer äußeren Erscheinung angeben zu können. (Leonhard 1817: 14 und 30, Böttiger 1817: 11).

Mehrere Monate nach seinem Aufenthalt in Freiberg begann Weiss den Briefwechsel mit Werner, ${ }^{32}$ als er erfahren hatte, dass Werner durch sein langes Schweigen enttäuscht war. In den Briefen bekundete Weiss die Verehrung für seinen Lehrer Werner stets höchst eindringlich. Es gelang Weiss dadurch, seinen Lehrer, der, wie bekannt, nur selten Briefe schrieb, mehrfach zu Antworten zu animieren. Dabei scheint Werner

\footnotetext{
${ }^{29}$ Weiss war offenbar bei Werner Gasthörer, über die es keine Nachweisungen gibt. - Freundliche Mitteilung vom Leiter des Freiberger Universitätsarchives, Herrn Dipl. Ing. oec. Hofmann.

${ }^{30}$ Das Ende der Reise Werners nach Paris ist belegt durch einen Brief von Karoline Herder an Knebel, wonach Werner, von Paris zurückkommend, am 11. 12. 1802 mehrere Stunden mit Goethe in Weimar gesprochen hat (Herwig 1965: 875, Steiger 1986: 331). Auch mit K. E. A. v. Hoff war er damals in Gotha zusammengetroffen (Mathé 1985).

${ }^{31}$ Anstöße für Werners Reise nach Paris können auch von anderen Schülern Werners ausgegangen sein, zumal er unter den zahlreichen ausländischen Schülern auch französische hatte. Nach der Übersicht von O. Wagenbreth (1957) waren dies A. J. M. Brochant de Villiers (1772-1840) (um 1795 in Freiberg) und J. F. d'Aubuisson de Voisins (1769-1841) (1797-1802 in Freiberg). Vor allem Letzterer, der 1801 schon über die oryktognostische Klassifikation Werners publiziert hatte, kann durchaus als Verursacher in Frage gekommen sein, da sein weiterer, im Mai 1802 in Frankreich erschienener Artikel eine ausführliche Gegenüberstellung der Methoden Werners und Haüys brachte (Daubuisson 1802). Dieser Aufsatz wurde später von Werners Mitarbeiter C. A. S. Hoffmann (1760-1813) in einer bearbeiteten und gekürzten Übersetzung publiziert (Hoffmann 1804). Da hierin u.a. der Schlussabsatz des Originals, der durchaus ein Ansporn für Werner gewesen sein könnte, weggelassen ist, wird er hier in Übersetzung gebracht:

.,Die Mineralogie ist unglücklicherweise keine so exakte Wissenschaft wie die Geometrie, nichts ist bei ihr scharf und genau; dieses Schwankende hängt mit der Natur der Gegenstände zusammen; und Bürger Haüy gebürt Dank, daß er Genauigkeit in den dafür geeigneten Teil hineingebracht hat. Wenn dieser Artikel zu dem geschätzten Gelehrten gelangt, bitte ich ihn, mich zu entschuldigen, wenn ich nicht immer seine Denkungsart verstanden und manchmal eine von ihm abweichende Meinung bekannt gemacht habe. Als Schüler der Mineralogie habe ich mir nicht angemaßt, einen Meinungsstreit mit einem erfahrenen Meister führen zu wollen; wahrscheinlich werde ich Unrecht haben mit dem Urteil eines Dritten. Unverzüglich werde ich gehen, ihn die Lektionen zu fordern, und ich werde sie hören mit dem mildesten Vorurteil: es ist die Schule von Werner, wo ich diese Meinungen geschöpft habe."

${ }_{32}$ Nur die Briefe von Weiss an Werner sind erhalten geblieben (SBAF-4). - Der Inhalt der Briefe Werners lässt sich in gewissem Maße aus den Gegenbriefen erschließen.
} 
weder von den massiv aufgetragenen Schmeicheleien noch von dem damit zum Teil verknüpften Eigenlob des Schreibers gestört worden zu sein. ${ }^{33}$

In seinem ersten am 8.9.1803 geschriebenen Brief an Werner (SBAF-4) teilte Weiss aus Leipzig mit, dass er im Sommer Vorlesungen über Chemie und ,.allgemeine Naturwissenschaft" ${ }^{* 34}$ gehalten hat und im Winter außer Chemie auch Mineralogie lesen will. Er wollte aber nur einen kurzen Abriss der Oryktognosie und der Geognosie geben. um seine Zuhörer zunächst mit der Mineralogie bekannt zu machen. Weiss fährt in dem Brief dann fort:

..Ihren Rat werde ich mir dafür mündlich ganz vorzüglich erbitten. Ich sehe voraus. daß ich ohne einen bestimmten Leitfaden. den ich zugrunde Iegen könnte. eine Arbeit übernehme. der ich [...] nicht ohne große Anstrengung gewachsen sein werde. Doch verspreche ich mir davon den größten Nutzen. wie die größte Freude für mich selbst. und wenn ich der Arbeit nur nicht unterliege. so wird gewiß jede Stunde. die ich darauf wende. Gewinn für mich sein. Möchte ich nach Beendigung dieser Arbeit mit eben der Freude über das Vollbrachte Ihnen Rechenschaft davon geben können. mit welcher ich jetzt sie übernehme! - Ihr Bild. Herr Bergrat. wird meinen Eifer beständig beleben und mich keinen $\mathrm{Au}$ genblick verlassen!*

Auf Werners Anraten hin legte sich Weiss eine Mineralsammlung an. Er durfte sogar Werner mitteilen, was ihm an Mineralen fehlt. besonders für den Aufbau einer ...̈̈ußeren-KennzeichenSammlung", die für die Mineralogielehre nach Werner ganz unentbehrlich war, und er erhielt von Werner entsprechende Stücke.

Bei der Übersetzung von Haüys Lehrbuch entwickelte Weiss eine andere Vorstellung über den Kristallbau als der Verfasser, die er mit Billigung von Karsten als zusätzliches Kapitel (Weiss 1804) in den ersten Band der Übersetzung einbrachte. Entsprechend den Gedanken Kants (Kant 1755. 1786), der von anziehenden und abstoßenden Kräften sowohl für die Bewegungen der Planeten als auch für die Erklärung des flüssigen und festen Zustandes ausgegangen war. sah er das Wirken solcher entgegengesetzter Kräfte für die Entstehung der Flächengestalt der Kristalle. vor allem für ihre Spaltflächen. entscheidend an, weshalb er seine Kristallvorstellung .,dyna- misch" ${ }^{35}$ nannte. Mit Kant lehnte er eine atomistische Vorstellung ab und hatte gegen Haüys grob atomistische Dekreszenz-Ableitung der Kristallflächen noch das spezielle Argument, dass bei der Aneinanderreihung von Elementarkörperchen in Oktaedergestalt die erforderliche volle Raumerfüllung nicht eintritt.

Der erste Band (Haüy 1804) erschien auf der Leipziger Michaelis- (Herbst-)Messe 1803. Weiss sandte ein Exemplar sobald als möglich an Werner. Ohne auf die Zusätze einzugehen, die er in diesen Band eingefügt hatte, teilte er im Begleitbrief am 31.10.1803 (SBAF-4) unter anderem mit:

..Ich nehme mir die Freiheit. Ihnen gegenwärtig den zu Ende dieser Michaelismesse erschienenen ersten Band der deutschen Übersetzung von Haüys Mineralogie zu überreichen. Statt der Schüchternheit, mit der dies vielleicht geschehen könnte oder sollte, bekenne ich Ihnen vielmehr die Zuversicht. mit der es geschieht. Und wenn ich mich über irgend eine Gelegenheit freuen darf, wodurch ich Ihnen meine unauslöschliche, feurige Dankbarkeit auch in einem äußern Zeichen an den Tag legen kann, so freue ich mich über diese, die dem. der Sie nicht kennt, weniger geeignet scheinen könnte. Ihnen meine Dankbarkeit auszudrücken, wenn nicht gar sie ganz in das Innere zurückzudrängen, und die doch gerade dadurch den Gipfel der Freude erreicht, daß ich es wagen darf, auch eine solche Schrift Ihrer entscheidenden Beurteilung mit Zuversicht zu übergeben. Ich übernahm. wie Sie wissen, den Anteil, den ich an der Erscheinung dieses Buches habe, noch ehe ich Sie kannte, noch ehe ich Ihr Schüler wurde. Sie kennen mich ganz; Sie sind über die Sicherheit, mit der ich bewundernd Ihre Mineralogie als die Mineralogie der Natur selbst kennen gelernt habe. über die innere Notwendigkeit des mit wahrer Wonne gefaßten Entschlusses, an Sie, an Ihr großes Vorbild. mich ewig anzuschließen, nicht in Zweifel; ich kann zur Empfehlung des Ihnen hier überreichten Buches, wenn es deren irgend bedürfte, nichts anderes, nichts Sprechenderes sagen. als daß es noch jetzt mich nicht gereut, dieses Geschäft übernommen zu haben, daß ich noch heute über die endliche. wirkliche Erscheinung der Übersetzung die aufrichtigste, von dem Interesse der Wissenschaft geleitete Freude habe. Ja mit diesem, einem würdigen Opfer feiere ich heute die Reformation der Mineralogie, die in 30 Jahren $^{3 h}$ emporgestiegen ist $\mathrm{zu}$ dem, was sie jetzt ist, und, unerschütterlich in ihren Grundfesten. durch denselben belebenden inneren Geist hervorrufen wird alle die Entwicklungen. denen Werner als ihr unmittelbarer oder mittelbarer Schöpfer in tatenvollem Bewußtsein freut und freuen wird. - Wollen Sie mein verehrtester Lehrer, mir hie und da einen Wink über etwaige Mängel oder Fehler, die Sie in dem Buche finden möchten, geben, so werden Sie meine Dankbarkeit sich aufs neue verpflichten. - Ich habe mir es übrigens nicht nehmen lassen, der zu sein, der Ihnen - ich hoffe doch. daß mir niemand zuvorgekommen sein kann -

33 Ein Beispiel hierfür ist der Brief vom 31.10.1803. siehe das Zitat weiter unten. - Über Werners Empfänglichkeit für Lob hat sein Zeitgenosse. der Amtsprediger in Freiberg S. G. Frisch (1825: 248) berichtet. Man gewinnt aus den Briefen von Weiss den Eindruck, dass auch ihm der Charakterzug Werners nicht verborgen geblieben war.

${ }_{34} \mathrm{Im}$ wissenschaftlichen Nachlass von C. S. Weiss (HASTB-3) befindet sich ein 23 Blatt umfassendes Manuskript von seiner Hand mit der Aufschrift .. Kants Mctaphysik“.

35 Diese Benennung deutete zugleich auf die Weiterentwicklung der Naturphilosophie Kants durch den „Dynamisten“ Schelling (Hermann 1977) hin. unter dessen Einfluss Weiss anfangs auch geraten war (Fischer 1963) (vgl. Anm. 43).

${ }^{36}$ Gemeint ist der Zeitraum sejt dem Erscheinen des Werkes von Werner (1774). 
unser gemeinschaftliches Werk $^{37}$ überreicht. Verzeihen Sie mir, wenn ich dadurch verursacht habe, daß dies nicht eine vielleicht noch liebere, auf allen Fall würdigere Hand dies tut. Der Geh. Oberbergrat Karsten ist es, den ich nun daran gehindert habe, aber mit dem ich nun gern und freiwillig die Freude, die jeder von uns damit sich machen wollte, teile. $[\ldots . . .]^{\text {c }}$

Karsten, den Weiss von seiner Sendung an Werner unterrichtet hatte, sandte selbst auch einen ersten Band der Haüy-Übersetzung an Werner und schrieb dazu (SBAF-5): ${ }^{38}$

„Herr Doktor Weiss hat mich zwar des Vergnügens beraubt, Ihnen mit einem Exemplar der von mir besorgten deutschen Ausgabe von Haüys Mineralogie aufwarten zu können. Dies soll mich aber nicht abhalten, Ihnen, mein unvergeßlicher Freund und Lehrer, die Versicherung zu erteilen, daß ich es in doppelter Hinsicht für meine Pflicht ansah, die deutsche Übersetzung dieses Werkes an Sie gelangen zu lassen, zuvörderst als einen geringen Beweis meiner fortdauernden unwandelbaren Hochachtung und hiernächst, um davon Veranlassung zu nehmen, einen Briefwechsel über die Benutzung des Eigentümlichen der Haüyschen Kristallographie anzuknüpfen, durch welchen ich freilich nur allein gewinnen kann, und es daher um so inniger erkennen werde, wenn Sie geneigt sein möchten, sich desselben zu unterziehen. Es ist sehr schade, daß der treffliche Veteran Haüy ${ }^{39}$ in frühern Zeiten nicht Gelegenheit gehabt hat, sich mit Ihrer Methode und namentlich mit Ihrer Charakteristik bekannt zu machen. Er wird dadurch in der Erkennung oder dem augenblicklichen Unterschiede der Fossilien stets mangelhaft bleiben. Auf der anderen Seite ist doch aber wohl unläugbar, daß die Reduktion der Prinzipien der Klassifikation auf mathematische Sätze - wenn sie auch nur bei einem Teil der Fossilien, nämlich bei den kristallisierten, Anwendung findet - zu einer wünschenswerten Zuverlässigkeit die Aussicht gewährt, welche außer der Mathematik nirgends zu finden ist. Daß die Natur selbst den Wegweiser enthält, beweist: Ihre schön gedachte Lehre vom Durchgang der Blätter, von den regelmäßigen Bruchstücken - beweist: die mechanische Zergliederung so mancher Körper, welche sich dazu eignen. Ich erwarte daher von einer Verbindung und Benutzung beider Methoden große Fortschritte für die Oryktognosie, und das ist mit der Grund, warum ich den wiederholten Anträgen nachgegeben und die deutsche Ausgabe des Haüy unternommen habe. - Gönnen Sie mir eine gütige Antwort hierauf, damit ich vorläufig erfahre, was Sie selbst davon halten."

Karsten brachte in diesem Brief noch verschiedenes Sachliche zur Sprache und schloss mit dem Vorschlag zu einer ,näheren Verbindung zwischen Freiberg und Berlin“, d. h. zu einer „Societät", die die Probleme der mineralogische Nomenklatur und Klassifikation diskutieren sollte. Werner ging hierauf aber nicht ein, es kam sogar viel schlimmer, wie sogleich gezeigt werden wird.

\section{A. G. Werners Haltung zu Haüy}

Auf den vorgenannten Brief von Karsten scheint Werner nicht geantwortet zu haben. Jedoch erhielt Weiss eine Antwort, die am 21.12.1803 eintraf, als er gerade im Begriff stand, nach Berlin zu reisen. Wie alle Wernerbriefe an Weiss ist auch dieser verschollen, hat aber noch vorgelegen, als der Neffe von Weiss einen biographischen Artikel über seinen Onkel verfasste. Wie man hieraus ([C.] E. Weiss 1880) entnehmen kann, hat sich Werner (Abb. 4) zunächst „sehr befriedigt" über den ersten Band der HaüyÜbersetzung geäußert, aber dann hinzugesetzt: „Aber, aber - warum konnte man nicht darin eine wahre und vollständige Parallele zwischen der deutschen und französischen Mineralogie ziehen? Dies alles konnte man ja füglich tun, ohne den Namen Werner zu nennen." E. Weiss

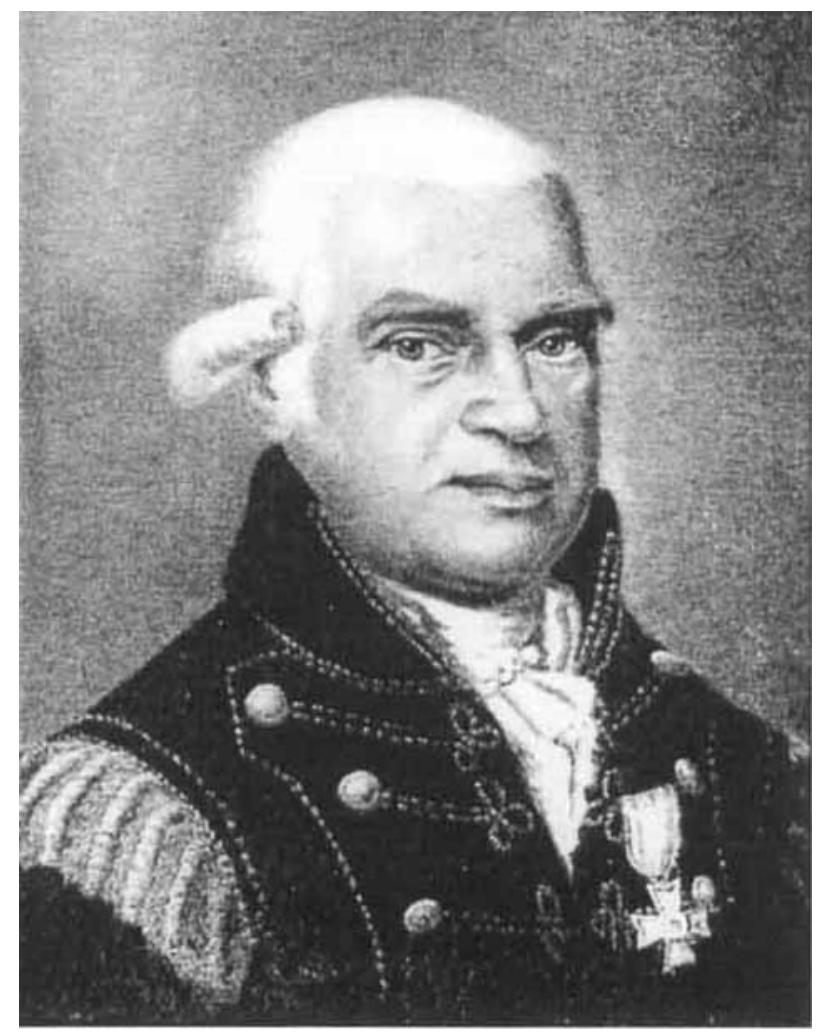

Abb. 4. Abraham Gottlob Werner (1749-1817). - Pastellbild, von unbekannter Hand geschaffen, in enger Anlehnung an das 1816 entstandene Porträt von M. Müller-Steinla, reproduziert aus W. Fischer (1936)

\footnotetext{
37 Am 1. Band der Haüy Übersetzung waren Weiss und Karstens Vetter als Übersetzer sowie Karsten selbst als Herausgeber, Verfasser des Vorworts und sehr vieler Fußnoten beteiligt.

38 Dieser Brief ist undatiert, kann aber nach seinem Inhalt zeitlich zwischen den Brief von Weiss an Werner vom 30.10. 1803 und den Antwortbrief Werners an Weiss, der am 21. 12. 1803 bei letzterem eintraf, eingeordnet werden.

39) Haüy war zu dieser Zeit 60 Jahre alt. - Das Alter von Werner betrug 54, von Karsten 35, von Weiss 23 und vom Vetter Karstens 21 Jahre.
} 
fügte noch an, Werner sei sogar sehr bitter geworden und habe geäußert: „Wo anders als in Ihrem Busen kann ich mein Herz ausschütten? ... Übrigens wissen Sie wohl, dass ich hier nicht für mich. sondern für die vaterländische Wissenschaft spreche und das ist mir teure heilige Pflicht. ..."

Dieser Brief beunruhigte Weiss sehr und veranlasste ihn zu zwei sehr langen Antwortbriefen (SBAF-4), einen noch am gleichen Tag und den zweiten nach seiner Rückkehr aus Berlin. Aus diesen Antworten von Weiss kann man schlieBen, dass Werner in seiner Kritik auf das von Karsten geschriebene Vorwort des Bandes hinzielte. Weiss ging im erstem Brief vom 21. 12. 1803 hierauf besonders ein. Nach ausführlicher Antwort auf einige hier unwichtige Äußerungen Werners schloss Weiss eine hohe Lobpreisung der Mineralauffassung Werners an und kam schließlich auf den Hauptpunkt der Verärgerung Werners, wobei er Karsten zu entschuldigen sucht. indem er ihm das tiefe Verständnis der Lehre Werners abspricht.

Wie verehre ich diesen Blick. so unübertrefflich scharf und ebenso umfassend! Wie labt mich diese Kultur der cinfachen Beobachtung, die, wie mir scheint, dem Menschen am meisten ziemt. und die bis zu einem Eindringen in die Gegenstände führt. das auf keinem anderen Wege schöner und in höherem Grade erreicht wird. die zu einer Kenntnis der Dinge leitet. ein Urteil über sie fällen lässt. das freilich nur als Orakel oder genialisches Glück denen erscheinen kann. die die unendliche Kultivierbarkeit jedes Sinns. jedes Organs der Beobachtung nirgends fühlen gelernt haben. Und so ist es. ich glaube. selbst mit den meisten sogar Ihrer Schüler. geschweige denn mit den Übrigen. Ich bin fest überzeugt. daß man Sie nirgends hinlänglich kennt. daß nur Bruchstücke der Kenntnis von Ihnen unter Ihren Schülern verbreitet sind. daß, wenn unter diesen gewisse sich zu ihrem großen Schaden nicht fest genug an Sie gehalten haben. der Grund dafür der ist, daß sie das Beste Ihrer ganzen Behandlung der Wissenschaft kaum ahnen. und dagegen von anderen, schlecht bearbeiteten, aber imponierenden und jetzt an der Tagesordnung stehenden Wissenschaften mit bestem Wissen und Gewissen irre geleitet sind ${ }^{+0}$. nicht aber. daß sie gegen Sie eingenommen oder daß ihnen gar. wic Sic sagen. Ihr Name gehässig wäre. Sie edler Mann - ganz als solcher zeigt mir Sie auch wieder Ihr mir wirklich heiliger Brief - lassen Sie auch noch diese Gerechtigkeit eines nicht bösen Willens Männern widerfahren. die vielleicht. wie Sie die Sache ansehen, Sie tief gekränkt haben. - Ich will Karsten nicht verteidigen. daß er nicht $z$. B. in der Vorrede. da er gerade den Flußspat wählte, nicht erwähnte. daß in Ihren Bestimmungen längst enthalten war. was Haüy jetzt vollständig geometrisch konstruiert hat. Allein. daß Karsten die ganze Ansicht Haüys vom integrierenden Molekül und der forme primitive. als durch alle kristallisierende Gattungen durchgreifend und für alle fest. wirklich für neu angesehen hat und nicht bloß die geometrische Herleitung der sekundären Formen aus jenen. welche. so viel ich weiß, wirklich neu ist, - davon bin ich fest überzeugt. Ich weiß, wie er überrascht war, aus der sechsseitigen Säule des Kalkspates den rhomboedrischen Kern herauspräparieren zu können; und schließen Sie daraus. wie wenig eingedrungen in die Sache man Ihren äußeren Beschreibungen überall nachgesprochen hat, woraus doch wahrhaftig diese Folgerung für jeden sich hätte von selbst verstehen sollen. Geben Sic aber zu, daß dies Karstens Gesinnung ist, so werden Sie eine Entschuldigung für ihn finden. wenn er auch in der Vorrede nicht glaubte, bei diesem zufälligen Beispiele auf Sie verweisen zu müssen, da er dachte. die Behandlung der regelmäBigen Bruchstücke als forme primitive pp. sei neu. - Nein, Sie stehen allein, weil man Sie nicht kennt. Man würde Sie verehren, wie ich Sie verehre. wenn man Ihren Geist ahnte. Und auch ich - ahne ich Sie nicht mehr, als ich Sie kenne? - Herr Bergrat! Ich bin sehr der Meinung, daß viel vorgängige Kultur dazu gehört. Sie zu fassen. mehr als die Menschen haben, die Sie hören. In Ihren Vorträgen liegt, glaube ich, der Keim zu jeder großen und wahren Ansicht der Wissenschaft. Aber Sie sagen diese Dinge so anspruchslos, so nebenbei, daß sie meist unbemerkt bleiben oder wieder vorübergehen. Auf Rechnung der Schwachheit. nicht des Willens der Hörer setzen Sie es, wenn Sie die Früchte vermissen, zu deren Erwartung Sie sich berechtigt glauben konnten. Und wenn es mir je in irgendetwas auf eine ähnliche Art gegen Sie gehen sollte. so bitte ich. mich nach dem nämlichen Maßstabe zu beurteilen. Nie kann es anders, als meinem ganzen Bestreben zuwider sein. etwas als Ihre Lehre zu verhehlen, wovon ich weiß. daß sie es ist und gewesen ist. Bei dem gegenwärtigen Falle der Haüyschen Übersetzung hoffe ich, daß Sie mich als außer dem Spiele betrachten."

Nach seinem Aufenthalt in Berlin äußerte sich Weiss im Brief vom 13.1.1804 an Werner (SBAF-4) nochmals im gleichen Stil zu demselben Thema, und bekräftigte seine Einschätzung von Karsten, den er über Werners Beanstandung unterrichtet hatte. Karsten sei auch von v. Buch, der viel später bei Werner gehört habe, in seiner Annahme gestärkt worden, dass Haüys Erkenntnisse völlig neu seien. Weiss fährt fort:

..Warum solte ich Ihnen dies alles nicht freimütig sagen? Die Hauptsache ist und bleibt, daß Ihre sämtlichen Schüler in die Tiefe Ihrer Ansichten und Ihres Blickes in die Natur des Gegenstandes gar nicht hineingekommen sind, und daß die äußeren Kennzeichen in ihren Augen und Händen nichts als lauter einzeine. wesentlich nicht ineinander eingreifende, tabellarisch aufzuzählende. nicht in Eins zusammenzufassende Bemerkungen sieht. die man an den Fossilien macht, nicht wie sie gleichsam aus den Fossilien herauskommen und ihr ganzes Wesen darstellen, äußern. - Ja, ich wette, daß Karsten erst. während ich mit ihm gesprochen habe, auf die Idee geleitet worden ist, daß doch wohl die regelmäßigen Bruchstücke offenbar nichts anderes sind, als die forme primitive. und daß das Feste, Bleibende der letzteren in allen Kristallen durch den bleibenden und bestimmten Durchgang der Blätter jederzeit gegeben gewesen ist. Indes gestehe ich, daß selbst. wenn man dies völlig durchdacht hatte, doch die Herleitung aller der mannigfaltigen Kristallisationsflächen aus lauter solchen sich ähnlichen regelmäßigen Bruchstücken, wo sie auch wirklich da waren, noch immer eine schwere. dunkle Aufgabe war, die doch Haüy erst auf seine

40 Hier ist zweifellos Karsten gemeint. der in seinen. für den mineralogischen Unterricht gedachten Tabellen (Karsten 1791/2, 1800) die Angaben 7.u den einzelnen Mineralen durch ihre chemische Zusammensetzung nach aktuellen Bestimmungen vervollständigt hat. Seine enge Zusammenarbeit mit dem Berliner Apotheker und Chemiker M. H. Klaproth steht damit im Zusammenhang. 
Weise gelöst hat, von der ich nun wiederum überzeugt bin, daß sie unrichtig ist, und $\mathrm{da} \beta$ an ihrer Stelle künftig eine ganz andere vollständige Strukturlehre als ein Hauptgegenstand der mineralogischen Physik treten muß."

In den letzten Zeilen dieses Briefes spielt Weiss auf seine von Haüy abweichende Vorstellung vom Bau der Kristalle an. Dies klingt aber nicht als Antwort auf eine Äußerung, die Werner über den Text Haüys oder über die Einfügungen von Weiss gemacht hat.

Werners Urteil über Haüys Mineralogie muss man also anderwärts suchen und erfährt es von L. v. Buch. Bevor dies hier zur Sprache gebracht wird, muss erwähnt werden, dass das Verhältnis v. Buchs zu Werner inzwischen durch ein anderes Problem schwer belastet war. Seit v. Buchs Italienreise von 1798/9 und - noch stärker seit seinem Studium der alten Vulkanlandschaft der Auvergne im Jahre 1802 waren v. Buch ernsthafte Zweifel an Werners neptunistischer Theorie der Vulkane und der Basalte gekommen. Zwar hatte er sich mit deren Bekanntmachung aus Rücksicht auf seinen Lehrer zurückgehalten, dennoch gelangte manches über Briefe v. Buchs, die veröffentlicht worden waren, und auch über C. S. Weiss ${ }^{41}$ direkt nach Freiberg, so dass v. Buch dort schließlich als Abtrünniger galt und eine Wiederholung des berüchtigten Neptunisten-Vulkanisten-Streites von $1789^{42}$ fürchten musste. Erst im Mai 1804, nach seinem 31/2-jährigen Aufenthalt in der Schweiz, war es v. Buch möglich, Werner in Freiberg aufzusuchen. Dort kam es dann zu längeren Aussprachen, worüber wir durch die publizierten Briefe v. Buchs an Karsten und durch Tagebuchnotizen v. Buchs unterrichtet sind (Schuster \& Bloch 1924: 26, Hoppe 1999c). Die Aussprache betraf zwar besonders das Vulkanismusthema, aber es wurde auch die Kristallographie Haüys ausführlich be- handelt. Glücklicherweise verliefen die Gespräche v. Buchs mit Werner in einer freundschaftlichen Atmosphäre und $v$. Buch teilt in einem kurz danach geschriebenen Brief an Karsten mit, dass Werner vorweg überraschend erklärt hatte, es sei „schändlich“, ,wenn er nicht erlauben wolle, dass man anderer Meinung sein könne, als er". Aber in Haüys Behandlung der kristallisierten Minerale sah Werner, wie v. Buch am 10.5. 1804 in sein Tagebuch notierte (HHMfN4), nur „bloße Spekulation“ und im Brief v. Buchs an Karsten vom 17.5.1804 (Schuster \& Bloch 1924) heißt es:

„Nein, mit Werners Urtheil von Haüy bin ich nicht zufrieden. Er ist nicht Mineralog, sagt er. Gut, das geben wir zu. er kennt die Mineralien nicht. Er hat eine Menge feiner und schätzbarer Bemerkungen zum Gebrauch [in] der Mineralogie gemacht, und ein entschiedenes und großes Talent für Kristallometrie zu einer mathematischen Spekulation angewandt. - O weit mehr. Was im Mineralreich das Fossil vom Fossile sondert, das hat zuerst Haüy gezeigt. ..."43

Etwa zur gleichen Zeit gab es einen heftigen Angriff gegen die Proklamation der Ideen von Weiss im 1. Band der Haüy-Übersetzung. Der englische Chemiker Richard Chenevix (1804, 1805), der bald auch Werner kritisierte, ${ }^{44}$ wies die dynamische Kristallvorstellung von Weiss der Naturphilosophie zu und erklärte sie für einen „widrigen Unsinn“. Seine Zitate aus dem Text von Weiss erweisen sich jedoch als mehr oder weniger entstellte Auszüge und zeigen, dass Chenevix nicht genügend in die Gedankengänge von Weiss eingedrungen ist. Man muss zwar zugeben, dass es Weiss einem schnellen Beurteiler durch seinen Stil nicht leicht macht, sich ihm zu nähern, Chenevix kann aber einer ernsthaften Prüfung nicht standhalten. - Neben Weiss wird auch Karsten in dem gleichen Chenevix-Artikel wegen der Herausgabe der Übersetzung, die er

41 L. v. Buchs Briefe an den Pariser Naturforscher J. C. de La Métherie und an den Genfer Physiker M. A. Pictet waren von diesen publiziert worden (v. Buch 1799, 1802/3, Hoppe 1994). Weiss gab im Brief an Werner vom 13.1.1804 seine Eindrücke weiter, die er am 28.12. 1803 persönlich von v. Buch an dessen Auvergnesammlung erhalten hatte (Hoppe 1999c).

${ }^{42}$ Dieser Streit, der zwischen Werner und seinem ältesten Schüler J. C. W. Voigt (1752-1821) über die Entstehung des Basaltes mit großer beiderseitiger Heftigkeit literarisch ausgebrochen war und weite Kreise zog, flaute zwar ab, blicb aber im Grunde unentschieden (Wagenbreth 1955).

${ }_{43}$ Werner blieb auch fernerhin bei seiner Einschätzung von Haüy, so dass sein Biograph, der Freiberger Prediger S. G. Frisch, nach Werners Tod mitteilte, dass Werner „Haüys Methode für unzureichend ansah, einen Oryktognosten zu bilden. und es auf keinen Fall für geraten fand, mit der Kristallometrie das Studium zu beginnen." (Frisch 1825: 255). Hierzu passt auch der von Weiss wiedergegebene Ausspruch Werners über die Verwendung von Haüys Kristallographie in der Mineralogie: „Das heißt ja die Wissenschaft depopularisieren." (Frisch 1825: 95).

${ }^{44}$ R. Chenevix (1774-1830) hatte sich 18 Monate in Freiberg aufgehalten und hatte sich dort, wie v. Buch in seinem Tagebuch notierte (HHMfN-4 vom 9. 5. 1805), 1804 in Freiberg als Privatmann ein Laboratorium bei dem Apotheker eingerichtet. In seiner Kritik Werners heißt es (Chenevix 1807): „In einer Abhandlung über einige mineralogische Gegenstände habe ich die Systeme der Herren Werner und Haüy miteinander verglichen, und ich gestehe Ihnen, ich bin für das Letztere. Dass man in Sachsen wünsche, die Mineralogie so gelehrt zu sehen, wie sie der Bergmann braucht, ist sehr natürlich; dieses führt aber zu einem methodisierten Empirismus, der nicht die Wissenschaft ist. Für den Bergmann ist die Methode Haüy's nicht; warum will man aber dem Naturforscher die Mittel entziehn, auf seinem Zimmer unsere Kenntnisse zu fixiren? In der Wissenschaft ist es mehr werth, sicher, als schnell zu bestimmen." 
von anderen hat anfertigen lassen, heftig angegriffen. Karsten verteidigt sich dagegen in ruhigem Ton (Karsten 1805). Weiss nahm die Kritik weit ernster, da er befürchtete. dass vom Vorwurf der Verbindung mit der Naturphilosophie. vor allem in ihrer Schellingschen Weiterentwicklung, ${ }^{45}$ eine schwere Gefährdung seiner angestrebten Laufbahn als Hochschullehrer ausgehen könnte, da sie in der Leipziger Fakultät verpönt war. Seine Antwort fiel deshalb auch sehr scharf aus (Weiss 1805).

Die Übersetzungsarbeit an Haüys Lehrbuch der Mineralogie ging inzwischen weiter und am 25. 5. 1804 konnte Weiss den 2. Band mit einem Begleitbrief an Werner senden (SBAF-4). Er kündigte wegen einer langen dienstlichen Inspektionsreise Karstens eine Unterbrechung auf etliche Monate an.. Im Übrigen scheint bei Weiss das Interesse an der Übersetzung des Lehrbuches der Mineralogie etwas nachgelassen zu haben, da er ein weiteres Werk, das Physiklehrbuch Haüys, in das er ebenfalls seine dynamische Kristalltheorievorstellung einbringen konnte, und schließlich sogar noch ein physikalisches Werk von L. Carnot übersetzte. Beide erschienen 1805 (Haüy 1804/5. Carnot 1803/5). Der 3. Band der Übersetzung von Haüys Mineralogie, woran Weiss auf der nun zu besprechenden mehrjährigen Studienreise gearbeitet hat. kam dann Mitte 1806 heraus.

\section{S. Weiss auf Studienreise 1805/8, Bekanntschaft mit R. J. Haüy}

Von Freiberg zurückgekehrt betätigte sich Weiss wieder als Privatdozent an der Universität Leipzig. Die Einkünfte, die er durch Betreuung des Studenten Christian Adolf Wendler hatte, ließen ihn an eine größere Reise denken und nach der medizinischen Promotion Wendlers im Oktober 1805 ging er mit seinem Zögling auf Reise, zunächst nach Berlin. Sein eigentliches Ziel stand aber fest. Man kann es im Besucherbuch des Königlichen Mineralienkabinetts in Berlin lesen. wo Karsten neben die Eintragung von Weiss am 3. 12. 1805 vermerkte: ,auf einer Durchreise nach Italien" (HHMfN-3). Den Winter über blieb Weiss in Berlin und kam in die Sitzungen der Gesellschaft naturforschender Freunde, wo er am 7.1.1806 einen Vortrag über seine ,dynamische Kristalltheorie" hielt. Über seinen Aufenthalt in Berlin teilte Weiss am 17.4.1806 dem Philosophen Friedrich August Carus mit (HASTB-4):

[Ich habe in Berlin] „unter einigen näheren Freunden, wiewohl Männern von 40-50 Jahren, eine Art kleiner Colonie angelegt, so daß sie nun, von meinen Ideen geleitet, meine Arbeiten zu den Ihrigen machen. Theils habe ich durch Humboldt, durch Joh. v. Müller u. a. Connexionen angeknüpft. die mir für meine weitere Reise überaus wichtig sind."

Die nächste Station war Wien, wo es bei längerem Aufenthalt viel Anregungen gab. Am 8.7.1806 schrieb er: „Das Meer der mineralogischen Schätze ist vollends kaum zu ergründen und in diesen schwimme ich herum bis zum Lahmwerden." In Wien wurde ihm aber auch klar, dass er die weitere Reise mit seinen begrenzten Mitteln nicht bestreiten kann, und er richtete ein Bittgesuch an seinen Landesherrn. den Kurfürsten Friedrich August III., der ihm schließlich 200 Reichsthaler pro Jahr bewilligte und dies an die Erkundung von wissenschaftlichen Fortschritten und Geräten band (Paufler 1981).

In München kam es (von nun an ohne Wendler) zum Zusammentreffen mit F. W. Schelling, dem führenden Naturphilosophen. Bei dem Gespräch mit Schelling ließ Weiss erkennen, wie sein Brief an den ältesten Bruder vom 11. 8. 1806 (HASTB-3) deutlich zeigt, dass er dessen Naturphilosophie zwar nahe stand, jedoch versuchte, Abstand zu halten:

..Ich bin von Anfang an ruhig, und als sey keine Feindschaft zwischen uns, gegen ihn gewesen, habe ihm bald darauf meine wirkliche Theilnahme gezeigt, die ich in der That an ihm habe. ihm dann ohne Hehl den Charakter meiner Studien als Cultur der lebendigen Anschauung geschildert, dic erst. wenn sie mit der Idee schlechthin coincidire, Naturwissenschaft werde: und wir kamen überein, daß die Idee, die nicht eher wirklich da sey, als bis sie auch in das ganz specielle hineingehe, doch erst den Dingen gegenüber geweckt werde: genug. ich hatte ihn dahin, wohin ich ihn haben wollte, gebunden an die Beobachtung."

Weiss wandte sich dann nach Genf, wo er den Winter verbrachte. In diese Zeit fällt auch ein mehrtägiger Besuch in Yverdon bei dem Pädagogen J. H. Pestalozzi (1746-1827), dessen dortiges Erziehungsinstitut ihn sehr interessierte.

\footnotetext{
45 Die dynamische Kristallvorstellung von Weiss beruhte zweifellos auf naturphilosophischen Ideen und zwar in ihrer ursprünglichen. Kantschen Form. aus der die inzwischen aktuelle. romantische bzw. spekulative Naturphilosophie Friedrich Wilhelm Joseph Schellings (1775-1854) entstanden war. Weiss suchte sich zunächst durch den Nachweis, dass er sich stets streng an Beobachtung bindet. davon abzugrenzen. In späteren Jahren zog er sich dann allmählich auf die rein mathematische Behandlung der Kristalle zurück und legte schließlich die naturphilosophische Motivierung seiner Kristallbehandlung vollständig ab (Fischer 1963).
} 
Im Übrigen brachte er in Genf die Übersetzung von Haüys Mineralogielehrbuch nicht weiter voran, unter anderem deshalb, weil er die Vorlesung über Experimentalphysik von M. A. Pictet (1752-1825) besuchte, - allerdings nicht als Schüler, sondern als Beobachter, wie er im Brief an seinen Bruder betonte. Besonders aber lenkte es ihn ab, dass er ,täglich vor- und nachmittags in einem interessanten Mineralienkabinett beschäftigt" war, wozu ihn der Besitzer, der mineralogisch interessierte Arzt L. Jurine (17511819), animiert hatte. Weiss bereute den großen Zeitaufwand nicht, da er, wie er mitteilte, „auch hier eine Art Pflanzschule“ seiner kristallographischen Ansichten und Arbeiten schuf. Außerdem empfand er es als gute Vorbereitung für seinen beabsichtigten Aufenthalt in Paris, zumal Jurine ihn bei Haüy ,prävenierte“, d. h. vorinformierte.

Aus Paris meldete sich Weiss am 18.5.1807 (HASTB-3) und vertraute seinem Bruder an, dass er aus finanziellen Gründen nicht lange bleiben kann, auch die Reise nach Italien fallen lassen muss. Vom Leben in Paris war er enttäuscht, da er mit der Präsentation einer Arbeit des Münchener Physikers J. W. Ritter (17761810) heftige Ablehnung erfuhr, ${ }^{46}$ und da er erkannte, dass „die persönlichen Bekanntschaften mit den Gelehrten, [...] um weiter zu führen, erfordern, dass man eine lange Zeit in Paris lebt." Er will deshalb baldigst in die Auvergne reisen. „Dort gibt es so viel zu sehen, dass ich nicht weiß, wie lange es mich aufhalten wird." ${ }^{47}$. Ein kurz darauf eintreffender, vom Bruder Fritz vermittelter größerer Kredit veränderte seine Lage bedeutend und ermöglichte es ihm, sogleich Pläne für den nächsten Winter in Paris zu machen, die er seinem ältesten Bruder im nächsten Brief vom 1.7.1807 mitteilte (HASTB-3). Dabei kommt er auch zu Erkenntnissen über sich selbst: „Mich trägt meine Natur überhaupt nicht zum Experimentieren, sondern zum Beobachten; und ich werde mich gegen diese innere Stimme durch keine andere, und sei es auch eine -
Dresdener, ${ }^{48}$ betäuben lassen." Er beschrieb auBerdem die Situation in Paris auf dem Gebiet der Naturwissenschaften, so wie er sie bis dahin kennen gelernt hat, und zur Naturphilosophie führt er aus:

„Kant ist noch immer im übelsten Geruch hier von der Welt: er muß alles ausbaden, was neuerlich Himmelschreiendes in Deutschland in den Wissenschaften verübt wird. Die Namen 'Fitsche und Schilleng' ${ }^{49}$ sind noch wenig geläufig; man mul3 sich noch immer auf sie besinnen und nimmt sie für rührige Prediger der Lehre des armen Kant. Mit diesem wird man vielleicht suchen, das Übel auszurotten."

Im August 1807 befand sich Weiss dann in der Auvergne. Leider erfährt man aus seinen Briefen, die er von dort schrieb, nichts von seinen Eindrücken und Ergebnissen, die er in dieser besonderen Landschaft gewonnen hat. Erst später zeigte sich, dass er dort und im benachbarten Vivarais an den alten Vulkanen Erkenntnisse erhalten hat, die wesentlich waren, über die er seinen Brüdern geschwiegen hat ${ }^{50}$. Jedoch fand er die Muße, nochmals über seine weitere Bestrebungen klar zu werden. Im Brief aus Clermont vom 12.8.1807 (HASTB-3) heißt es dazu:

„Meine Neigung geht immer auf Nachdenken über eine vorliegende, warm gefühlte Anschauung. Im Verfolgen dieser ist mir wohl in meinen Arbeiten, sonst kaum je. Bloß ungefühltes Sammeln und Zusammenscharren oder Aufschreiben. eine Art von Auswendiglernen, Experimentieren ohne imneren Zug, ist meine Sache nicht. Meine Sache ist: Sehen, dem Gefühl dabei Nachgehen und Denken. [...] Aber laßt mir den buntscheckigen Tand von Instrumenten und Instrumentchen, Experimenten und Experimentchen vom Halse. Ich will schon auch dahin sehen, wenn es Zeit und Stunde bei mir ist, aber dann werde ich es auch übersehen und nicht gaffend drin stehen." Er nimmt sich weiterhin vor, sich so sehr als möglich „vor einer Phantasieschöpfung und Phantasieforderung zu hüten, ganz nüchtern, ganz prosaisch sein, klar sehen und klar sehen wollen, was ist, und zufrieden sein damit."

Als Weiss dann wieder in Paris ist, entwickeln sich seine Beziehungen weit besser und in einem Brief an seinen ältesten Bruder vom 7.3.1808 (HASTB-3) heißt es unter anderem:

„Meine Verhältnisse in Paris sind recht sehr gut. Mein literarischer Credit hat sich während meines zweiten Aufenthalts sehr vermehrt. Haüy ist wie ein Ohrwürmchen, und wenn die genaueste Kenntnis dazu hinlänglich wäre, so wärc ich gar sein Herzblättchen. Er weiß sehr gut, daß niemand die Sache

\footnotetext{
46 Aus Freundschaft mit Ritter hatte Weiss in Paris über ein Instrument berichtet (Weiss 1807), das Ritter zusammen mit dem italienischen Rutengänger Campetti zur Bestätigung der Wirkung einer Wünschelrute entwickelt hatte.

${ }^{47}$ Weiss hatte einiges über die Beobachtungen v. Buchs in der Auvergne erfahren und er wollte diesen wohl nachgehen.

4\$ Weiss vermutete gewisse Bedingungen der sächsischen Regierung für die Vergabe der von ihm angestrebten Physikprofessur in Leipzig.

${ }^{49}$ Gemeint sind die deutschen Philosophen J. G. Fichte (1762-1814) und F. W. J. v. Schelling. deren Namen Weiss anscheinend so schreibt, wie sie aus französischem Munde anzuhören waren. Beide waren Anhänger von Kant, wobei sich der Erstere auf philosophisch-theologischem Gebiet betätigte (Fischer 1963). - Von beiden hatte sich Weiss stark angezogen gefühlt, von Schelling nur anfangs. Vgl. dazu Anm. 45.

50 Er wollte wohl vermeiden, dass seine Beobachtungen verbreitet wurden, um nicht in Freiberg, wie v. Buch, in Ungnade zu fallen.
} 
besser versteht als ich. sogar er selbst nicht. Berthollet ist mir sehr gewogen und durch ihn die Société d Arcueil. ${ }^{51}$ Die jungen Leute sind aufmerksam geworden und haben etwas Respekt gekriegt. Brochant, der beste unter allen jungen französischen Mineralogen, und ich sind intime Freunde und gerade er erkennt am reinsten und unbefangensten die Uberlegenheit an, die mir die Wernersche Schule und meine eigenen Arbeiten über ihn gegeben haben. ${ }^{55}$

Auf den beiden letzten, eng beschriebenen Seiten dieses achtseitigen Briefes schildert Weiss seinen Tageslauf in Paris, woraus hier vor allem interessiert, dass er bei Haüy regelmäßig Besuche von meist mehreren Stunden machte. Er spricht auch nochmals von Freundschaften. Von den älteren Gelehrten hält er sich vor allem an Haüy und an Berthollet. Mit Chenevix hatte er .einen neuen Tanz" wegen eines Artikels, mit dem dieser die Methode Werners angegriffen hatte (Chenevix 1808), ${ }^{53}$ und arbeitete an einer Erwiderung, die er aber nicht veröffentlichte.

\section{Berufung von C. S. Weiss auf den Physik- lehrstuhl in Leipzig, Bruch mit R. J. Haüy}

Am 17.3. 1808 wurde durch den Tod des Professors K. F. Hindenburg die Leipziger Physikprofessur frei, deren Erlangung das seit langem erhoffte Ziel von Weiss war ${ }^{54}$ und er bewarb sich sogleich mit einem lateinischen „Anhaltungsschreiben". In der folgenden Wartezeit in Paris. in der er zunächst recht zuversichtlich war, trat noch ein Ereignis ein, das seine Situation abrupt veränderte. Es betraf sein Verhältnis zu Haüy, worüber er am 6. 6. 1808 in einem Brief an seinen ältesten Bruder wie folgt berichtete (HASTB-3):

.. "Vous êtes perdu de reputation" [Sie haben ihren Ruf verspielt]. sagte mir neulich Haüy ( - unter uns) nach einem ganzen Winter voll Freundschaftsbezeugungen. öffentlicher. wohl abgemessener Lobsprüche. die er als Lockspeise mag gebraucht haben. entschiedener Anerkennung meiner Kenntnisse, wozu er nicht leicht einen findet, der sie. eben wie sie sind, aufwiegt, wirklichem innern Respekt davon. und das weiß ich, auch zu Zeiten sogar unläugbar persönlicher Zuneigung zu mir. «Vous êtes perdu de reputation» - weil ich seine Theorie über die Kristalle nicht unterschreibe. weil ich eine andere habe. die er nicht begreifen kann und die ich mir nie die Mühe gegeben habe, ihm begreiflich machen zu wollen, was unmöglich ist. Vous êtes perdu de reputation. «Je n'en serai pas plus malheureux» [Ich werde deswegen nicht unglücklicher sein], hatte ich auf den Lippen. Aber ich blieb noch kälter, noch indifferenter. Warum soll es denn am Ende nicht verschiedene Meinungen über gewisse Dinge geben? sagte ich ihm und noch zuletzt ganz nachlässig; und warum nicht einen gewissen Punkt, wo man einem gar nicht mehr beweisen könnte, wenn man auch wollte. Diese Halsstarrigkeit, diese Unveränderlichkeit in seinem Sinn - er kennt mich nun seit mehr als einem Jahre - dieses Scheitern alles des gehofften Einflusses von Paris nach einem so langen Aufenthalt bei sonst so vollkommener Bescheidenheit, Ruhe, Rechtlichkeit, unläugbar gutem und richtigem Kopfe und scharfen Kenntnissen, - diese Unerschütterlichkeit in etwas ihm Unbekanntem, im Hintergrund Liegendem, gar nicht ans Licht Hervorzuziehendem und dann Totzuschlagendem. muß allerdings für ihn neben dem höchst Erbitterndem auch etwas Magisches, Gespensterartiges haben, worüber er mit seinem Hasse nicht einmal fertig werden kann, was ihn schreckt und ihm Entsetzen macht bei Tag und Nacht. - Ich habe bisher ungemein gut mit ihm gestanden, er hat Proben genug. wie und wo ich sein Verdienst anzuerkennen mich beeifere: er weiß es nur zu klar, worin ich es anerkenne, aber er ist damit nicht zufrieden. Herrschsüchtig und despotisch, gleisnerisch und geschmeidig dabei, wie mehr oder weniger fast alle Pariser von Einfluß sind, will er mehr; und da ist der Nacken unbiegsam. Das sieht er nun, wiewohl ich ihm von dem zweiten Theile, wo wir divergieren, gar nie spreche; das hat er für unmöglich gehalten, und nach hinlänglicher Erfahrung dies nun als endliches Resultat zu sehen, empört ihn. So hat er denn endlich den Entschluß gefaßt, förmlich mit mir zu brechen; und auch das ist ihm bei seiner unbegreiflichen Kälte - nicht völlig gelungen."

Nachdem Weiss dies geschrieben hatte, muss ihm der Brief aber nicht zum Versenden geeignet erschienen sein, denn er brach den Text ohne Schlusssatz $a b$ und die angefangene Seite blieb zu einem Viertel leer. Auch teilt er seinem Bruder Benjamin 10 Tage später mit, er habe dem älteren Bruder einen Brief „längst geschrieben, aber nicht geendet". Der Grund für die Zurückhaltung des abgebrochenen Briefes lag wohl darin. dass ihm die zu erwartenden Vorwürfe seiner Brüder unangenehm waren, zumal er eigentlich die Reaktion von Haüy sich selbst zuzuschreiben hatte und ihm bekannt geworden war, die Leipziger Fakultät habe ihn nur an die zweite Stelle ihrer Berufungsliste gesetzt. ${ }^{55}$ Diese Lage veranlasste ihn zu Briefen an Personen der Regierung und sogar an den sächsischen König persönlich

\footnotetext{
51 Claude Louis Berthollet (1748-1822), Pariser Chemiker und Physiker, Mitglied des Instituts, gründete 1807 eine Privatgesellschaft in seinem Wohnort Arcueil bei Paris

52 André Jean Marie Brochant de Villiers (1772-1840) war jedoch 12 Jahre früher als Weiss Schüler von Werner gewesen (Wagenbreth 1957) und hatte sogar ein Mineralogielehrbuch nach Werners Lehre publiziert (Brochant 1801/3).

${ }_{53}$ Es handelt sich um eine sehr ausführliche, aber einseitig orientierte Gegenüberstellung der Methoden von Haüy und von Werner. die sich gegen Werner richtete.

${ }^{54}$ Auch in der sächsischen Landesregierung hatte man in Weiss den möglichen Nachfolger von Hindenburg gesehen, wie aus den Akten über das Stipendium für seine Studienreise 1807 hervorgeht (Staatsarchiv Dresden Loc. 4865 Bd. 1, nach: „Akten uber die Bergakademie Freiberg im StaD”. betr. C. S. Weiss. Bl. 199a und b.) - Für die Mitteilung danke ich Herrn Dipl.-Ing. oec Hofmann. Leiter des Universitätsarchivs Bergakademie Freiberg).

55 An der ersten Stelle stand der Professor der Physik an der Universität Halle, Ludwig Wilhelm Gilbert (1769-1824). Gilbert erhielt die Stelle erst später. nachdem Weiss nach Berlin gegangen war.
} 
(Paufler 1981), denen gegenüber er seine Befähigung ausdrücken zu müssen glaubte. ${ }^{56}$ Er hatte damit Erfolg und seine Berufung erfolgte am 26.7.1808. Nun machte es ihm nichts mehr aus, den unvollendeten Brief am 22.8. 1808 an seinen ältesten Bruder zu senden und ihn aufzufordern, sich recht freimütig zu äußern, wie er es von Jugend an getan hätte, ,auch eher streng“.

Weiss verließ nun Paris mit einem Umweg durch die Schweiz und begann seine Vorlesungen in Leipzig noch im Wintersemester 1808. Dies erfährt man aus einem Brief vom 20.11. 1808, mit dem er den Briefwechsel mit Werner nach dreijähriger Pause wieder aufnahm (SBAF-4). Er las nun neben einer allgemeinen Einführung in die Physik viertägig über Elektrizität und Galvanismus mit Versuchen. Wie er weiter schrieb, könne er sich mit Mineralogie jedoch nur in zweiter Linie beschäftigen, hielte aber die Richtung seines nunmehrigen Berufs für ,sehr wohltätig und erwünscht“ und wäre "mit ganzer Seele" in seinem Berufe.

Für die offizielle Antrittsvorlesung am 8. 3. 1809 griff Weiss auf seine kristallographischen Studien zurück und behandelte in lateinischer Sprache die Themen „Über die Erforschung des geometrischen Hauptcharakters der Kristallformen" und drei Tage später: „Über den geometrischen Hauptcharakter oktaedrischer Kristallformen mit geraden Pyramiden auf länglich rechtwinkliger Basis" (Weiss 1809). ${ }^{57}$ Hierin führt Weiss, anknüpfend an Haüy und an Romé de l'Isle nebst dessen Würdigung als erstem, auf Bergman aufbauendem Kristallforscher, ${ }^{58}$ eine mathematische Behandlung der Kristalle vor, die seiner Vorstellung des Kristallbaus entsprach. Aus den Flächenabmessungen der Grundkörper Haüys leitete er die Neigungen der Flächen zu derjenigen Achse ab, zu der sie symmetrisch angeordnet sind. Er verband damit die Vorstellung, dass sich in solchen Achsen die Hauptrichtungen der Kristallisationskräfte widerspiegeln. Anhand dieser Achsen vermochte er, die Kristallarten untereinander $\mathrm{zu}$ vergleichen, was bei Haüy fehlt. Als Weiss dann am 13.3. 1809 ein Exemplar der Antrittsvorlesung an Werner sandte (SBAF-4), begleitet er dies mit Betrachtun- gen über die Wirkungen, die seine Darlegungen haben dürften, und er glaubt, Haüy müsse seine Überlegenheit über ihn spüren.

Bald darauf hatte die Antrittsvorlesung die Folge, dass Weiss von dem Jenenser Mediziner und Naturphilosophen L. Oken (1779-1851) gebeten wurde, sich über Haüys Mineralogielehrbuch und über die Auslassungen von Chenevix zu äußern, da Oken dies in seinem Lehrbuch der Naturphilosophie, das er gerade ausarbeitete (Oken 1808/11), verwenden wollte. Weiss gab in einem zehnseitigen Brief vom 3.5.1809 (HASTB-4; Schuster 1922: 97-103) ausführliche Auskünfte, in denen er sowohl die Verdienste als auch die Schwächen und Fehler Haüys darstellte, dazu die Erkenntnisse, die er selbst gewonnen hat. Hierzu fügte er ein:: „Die Form, die Figur soll dynamisch erklärt werden. Damit habe ich das große Werk angefangen, in dessen allmählicher Ausführung ich wohl zeitlebens begriffen bleiben werde." Er wies auch auf die Beispiele seiner Kristallbetrachtung von Feldspat, Epidot und Glimmer ${ }^{59}$ hin und er wiederholte, was er in diesem Zusammenhang an den Herausgeber der Übersetzung, an Karsten, geschrieben hatte: „Nun weiß ich gewiss, dass nun, wenn ich morgen sterbe, das, was ich für die Kristallisation gewollt habe, nicht mehr untergehen könne, sondern gewiss einmal ein empfängliches Gemüt wieder aufregen und in ihm das wieder lebendig machen müsse, was ich gefühlt hatte, wenn ich es auch nicht selbst vollenden konnte." - Am Ende des Briefes ging Weiss dann noch auf die von Oken gewünschte Stellungnahme zu den kritisch-polemischen Artikeln von Chenevix ein, die er aber nun als "Chenevixiaden“" abtat und nicht mehr ernst nahm.

\section{S. Weiss wird Nachfolger von D. L. G. Karsten an der Berliner Universität}

Die letzte große Wende im Leben von Weiss trat ein, als D. L. G. Karsten mitten in der Gründungsperiode der Berliner Universität am 20. 5. 1810 verstarb. Karsten hatte an den Vorbe-

\footnotetext{
56 Auch Werner hatte sich für Weiss eingesetzt. Dies geht aus dem Brief von Weiss an Werner vom 20.11 .1808 (SBAF-4) hervor.

57 Diese Abhandlungen wurden bald danach von dem mit Weiss befreundeten Chefingenieur des französischen Berg-Korps, A. J. M. Brochant de Villiers, in französische Sprache übersetzt und etwas gekürzt publiziert (Weiss 1811) (Groth 1926: 61-65).

58 Der Passus über Romé de l'Isle fehlt in der Übersetzung von Brochant de Villiers. - Romé de l'Isle zeichnete sich unter anderem auch dadurch aus, dass er Winkelmessungen an Kristallen vornahm, was Haüy und Weiss nicht taten. Ihnen genügten für ihre Rechnungen die Messungen anderer. Weiss bezweifelte später sogar den Wert genauerer Messungen.

59 Diese Ausführungen finden sich in: Haüy (1804/06/10), Bd. 2, S. 711 sowie Bd. 3, S. 132 und 269.
} 
reitungen zur Universitätsgründung aktiv teilgenommen und stand für die Berufung zum Professor der Mineralogie an, da der laufende Ausbildungsbetrieb der Berliner Bergakademie. an der er Mineralogie lehrte. mitsamt dem königlichen Mineralienkabinett. wie bereits dargestellt (Hoppe 1999a), der Universität übertragen werden sollte. Zugleich war Karsten vor wenigen Wochen zum Leiter und ranghöchsten Beamten

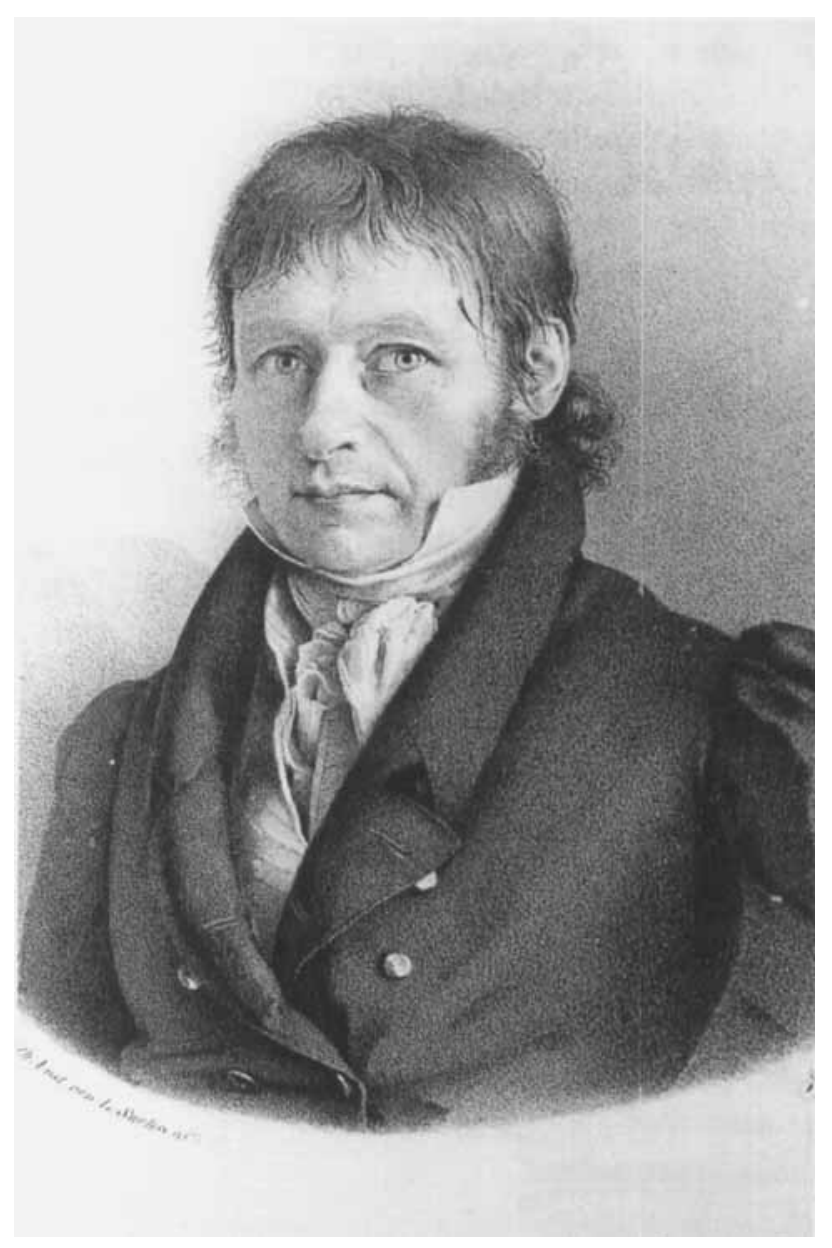

Abb. 5. Christian Samuel Weiss (1780-1856). - Lithographie. Original: Porträtsammlung der Humboldt-Universität. Universitätsbibliothek des preußischen Berg- und Hüttenwesens ernannt worden. Sein Tod riss eine empfindliche Lücke, die für das Bergwesen durch Ludwig Gerhard (1768-1835), den Sohn des ursprünglichen Gründers der Bergakademie Karl Abraham Gerhard (1738-1821), geschlossen wurde. Für die Universität musste ein anderer Ersatz gesucht werden.

In dieser Situation wurde L. v. Buch aktiv und legte einen Vorschlag zur Besetzung der Professur für Mineralogie in Berlin vor. Das Zustandekommen dieses Vorschlages kann nach den Notizen im Tagebuch v. Buchs (HHMfN-4) verfolgt werden. Der Tod Karstens hatte v. Buch tief getroffen und er vertraute seinem Tagebuch nach einer Lücke am 27.5.1810 an: ,und nun Karstens Tod. den ich bitter und schmerzlich empfinde und stets empfinden werde, der Nächste, der Liebste der Freunde, die Seele und das Bewegende alles Guten und Vortrefflichen um mich her." ${ }^{60}$ Am gleichen Tage begann v. Buch eine große Reise, die ihn in die Schweiz und in die französischen Alpen führen sollte, und traf am Morgen des 29.5.1810 in Leipzig ein. Nun heißt es in seinem Tagebuch:

.Ich suche Weiss auf und finde ihn im Boseschen Garten. Bescheiden. wie ich ihn vorher nicht kannte. Nach Mittag zeigt er mir seine sehr wichtigen Sachen aus Vivarais. ${ }^{61} \mathrm{Er}$ hat viel und gut gesehen. Und ich rechne dies zu unerwartet lehrreichen Stunden. Viele Wochen haben mir nicht Ansichten eröffnet. wie hier ein Augenblick. - [30. 5. 1810] [...] zu Weiss. wo ich jetzt gern bin. Er ist guter Geognost, denn er hat sich lebendig bewegt in den Alpen und in Frankreich. Und ließ. wie sich denken läßt. Steffens ${ }^{62}$ tief sinken. Nach Mittag zeigt uns Dr. Gehler, des Arztes Sohn, seine Sachen von Vivarais. die fast nur Schlacken sind, und an Interesse denen schönen Stucken von Weiss nicht gleichkommen. Ich bin in Weiss Kollegium der Physik. Zur Mineralogie gehört er. Nicht zur Physik. Seine Gedanken sind nicht geordnet. Nichts Stetiges in seinem Vortrag. Nichts Fließendes. Die Physik hat überhaupt weniger Reize für ihn, als das Genaue der Mineralogie. Ich scheide doch mit Achtung von ihm. Er ist voller Kenntnis und kann sehr nützlich werden."

Wenige Tage nach dem Besuch in Leipzig entschloss sich v. Buch, der inzwischen bis nach

${ }^{60}$ Dieses tiefe Gefühl drückt sich auch sehr deutlich in der ..Lobrede* aus, die v, Buch als Nachruf auf Karsten am 3.7. 1814 vor der Berliner Akademie gehalten hat (v. Buch 1818)].

th Die Landschaft Vivarais in Frankreich. die v. Buch nicht besucht hat. liegt ostlich der Auvergne und besitzt ebenfalls wie Letztere alte Vulkane.

$6^{2}$ Der aus Norwegen stammende Henrik Steffens (1773-1845) war damals Professor der Naturphilosophie, Physiologie und Mineralogie in Halle. später in Breslau, ab 1832 Professor der Philosophie in Berlin.

6. Der Adressat war vermutlich Wilhelm von Humboldt. der Initiator der Universitätsgründung in Berlin, den v. Buch persönlich kannte und hoch schätzte.

ht Gemeint ist das Königliche Mineralienkabinett des Preußischen Berg- und Hüttenwesens, das von der Berliner Bergakademie als Lehrsammlung genutzt wurde.

*5 Der Erfurter Professor Johann Jakob Bernhardi (1774-1850). der sich bevorzugt botanisch, aber auch mineralogisch betätigte. brachte 1809 eine Kritik der Ansichten von Haüv wie auch von Weiss mit tiefen Einsichten heraus (Bernhardi 1809, Groth 1926: 65).

th L. v. Buchs Ansichten über die Basaltbildung und dic Vulkane hatten sich inzwischen zwar weiter gefestigt (Hoppe 1994). trotzdem interessierten ihn weitere Beobachtungen und Ergehnisse sehr. 
Gotha gekommen war, für Weiss in der Frage der Besetzung der Berliner Mineralogieprofessur einzutreten und sandte folgendes Schreiben am 3. 6. 1810 nach Berlin (Lenz 1910, 4. Bd.: $114-6):^{63}$

"Was auch über das Kabinett ${ }^{64}$ bestimmt werden mag, ich versichere Sie, Weiss in Leipzig ist der Mann, dem man es anvertrauen muß. Er wird Karsten nicht ersetzen; allein man würde ihn auf anderen Seiten sich jetzt nicht besser selbst machen können. Weiss ist Professor der Physik. Dazu hat er aber nicht Neigung und nicht Eifer. Wohl aber für alles, was Mineralogic und Chemie angeht. Er ist, außer Bernhardi in Erfurt, ${ }^{65}$ der einzige, welcher Haüys Methode gründlich studiert hat; und ohne diese kristallographische Ansicht wird es nie eine vernünftige Mineralogie geben. - Denn eben das ist Zweck der Mineralogie, die Form zu untersuchen und die Gesetze ihrer Veränderung. Haüy selbst nennt Weiss einen sehr geschickten Kristallographen. Er hat aber die Wernersche Ansicht, welche die Mineralien erkennen lehrt, ebenso gut sich zu Eigen gemacht, und das unterscheidet ihn wesentlich von Bernhardi. Weiss hat ganz das Sorgsame, was einem Direktor einer Sammlung zukommt, und recht viel Sinn für Schönheit und scientiven Wert der Stücke. [...] - Weiss ist jetzt gar nicht an seinem Platz. [...] Er liest auch Naturphilosophie; allein sie hat auf seine Untersuchungen gar wenig Einfluß. Er umfaßt eine zu große Masse von faktischen Kenntnissen, um nicht mehr Gründlichkeit und Wahrheit $\mathrm{zu}$ suchen, als den naturphilosophischen Physikern gewöhnlich zu Gebot stehen. Weiss hat alle Täler der Alpen gesehen, mit einer Mühe und Ausdauer, die ich bewundere; [...]. Und ebenso unbefangen und scharfsichtig die Vulkane von Vivarais und Auvergne. Dadurch habe ich in zwei Tagen mehr bei ihm gelernt, als in zwei Jahren vorher. ${ }^{66}$ Weiss ist wohl geneigt zu kommen; das große Kabinett reizt ihn gar sehr; und auch wohl viel der Ehrgeiz, hierinnen Karstens Nachfolger zu sein. Aber, da er gut steht, so müßte er auch gut wieder gesetzt sein. Von der Universität als Mineralog ein kleines. Als Aufseher des Kabinetts, dann von dem Eleveninstitut. Dann sollte ihn die Bergwerkdirektion als Rat oder Assessor unter sich aufnehmen. Denn eines Mineralogen Rat könnte ihr oft nötig sein. [...] - Ich kenne in Deutschland niemand, den ich ihm auch nur gleich stellen möchte. [...]".

Die Empfehlung v. Buchs fiel auf günstigen Boden und ihr wurde in allen Punkten gefolgt. Der Ruf an Weiss erging am 25.7.1810 mit der $\mathrm{Zu}$ sicherung eines Gehaltes von insgesamt $1500 \mathrm{Ta}$ lern (GSTAB-13), mehr als das Doppelte des Gehaltes, das Weiss in Leipzig bekam. Das Angebot aus Berlin war für Weiss aber nicht nur in finanzieller Hinicht außerordentlich günstig, vielmehr entsprach es durch die anstehenden Aufgaben seinen wissenschaftlichen Ambitionen unvergleichlich besser als das Amt, das er in Leipzig innehatte. So ist es verständlich, dass er sogleich, noch am 2.8.1810, seinem älteren Bruder schrieb (HASTB-3), dass er ziemlich entschieden sei, „dass dort mehr mein Platz als hier" ist, jedoch bittet er zunächst noch in Berlin um nähere
Auskünfte. Ferner wandte er sich am 6.8.1810 (SBAF-4) auch an Werner, um dessen Meinung zu erbitten und einen Rat zu erhalten, und erörtert im Brief ausführlich alle Aspekte des Rufes nach Berlin, bis hin zu der Frage:

„Ob Sie es nicht mit einiger Liebe denken könnten, daß ich in Berlin als Sprecher über Mineralogie aufträte und manches mineralogische Band, welches der von Ihnen zu sehr und wissenschaftlich zu seinem entschiedenen großen Schaden losgerissene, übrigens dennoch und auch von mir geliebte und geschätzte Karsten zu meinem steten Leidwesen vernachlässigte, ${ }^{67}$ zwischen Berlin und Ihnen sich wieder enger knüpfte?“*

In einem Postskriptum teilt Weiss in diesem Brief noch mit, dass der 4. Band der Übersetzung von Haüys Lehrbuchs der Mineralogie, den er durch Einarbeitung von Haüys inzwischen erschienenem „Tableau comparatif“" (Haüy 1809) vervollständigen konnte, nun zur Michaelis(d. h. Herbst-) Messe gedruckt vorliegen wird. Damit wurde das von Karsten im Jahre 1802 eingeleitete Unternehmen endlich abgeschlossen, allerdings erst nach Karstens Tod.

Die erhoffte Zustimmung Werners zur Annahme seiner Berufung nach Berlin erhielt Weiss nicht. Werner schreibt ihm auch nicht selbst, sondern ließ ihm ausrichten, er solle in Leipzig auf seinem vaterländischen Posten bleiben. ${ }^{68} \mathrm{Am}$ 28. 8. 1810 teilte er dann Werner mit (SBAF-4), er wäre noch nicht entschlossen, da er durch ungünstige Nachrichten von Freunden aus Berlin "einigermaßen zum Wanken gebracht" sei. Aber er deutet an, dass er wohl doch nach Berlin gehen wird, und schreibt: „In kurzem erfahren Sie meine endliche Entscheidung." Er hatte sich aber bereits endgültig für Berlin entschieden, denn am gleichen Tage sandte er sein Entlassungsgesuch an den sächsischen König (Paufler 1981) und die Zusage für Berlin hatte er schon am Vortage geschrieben (GSTAB-14). Am 18.10.1810 nahm Weiss Abschied von Leipzig und trat kurz danach seine Professur in Berlin an.

Hier ist nun der Ablauf chronologisch an der Stelle angelangt, an der ein neuer Teil der Geschichte der Berliner Geowissenschaften einsetzt, der im nächsten, 4. Teil der vorliegenden Artikelreihe behandelt werden soll: Trotzdem sollen den Abschluss des vorliegenden Artikels noch zwei Briefe bilden, die Weiss (Abb. 5) über seinen Beginn in Berlin geschrieben hat.

\footnotetext{
67 Weiss wiederholt hier nochmals die Meinung über Karsten, die er in den Briefen vom 21. 12.1803 und vom 13. 1. 1804 (s.o.) Werner mitgeteilt hatte und mit der er offenbar erwartete, Werner nochmals für sein Anliegen günstig zu stimmen.

${ }^{68}$ Erschlossen aus den Briefen von Weiss an Werner vom 22.8.1810 und 10. 4. 1811 (SBAF-4). Die Worte Werners waren Weiss „,durch die Frau Kreissteuereinnehmerin Weisse" übermittelt worden.
} 
Der erste dieser Briefe, vom 14.11.1810 (SBAF-4), ist an seinen ältesten Bruder gerichtet, dem er sich wieder voll öffnet:

„Meine richtigere Stelle [...] war doch $[. .$.$] hier in Berlin: so$ dachte ich, als ich dort wegging. und so denke ich noch, nachdem ich doch aus dem Gröbsten gesehen habe, wie ich mich hier befinde. [...] Denke dir mich höchst einfach. sehr einsam hier lebend, gänzlich anspruchslos, gänzlich mit dem zufrieden, was ich wirklich mein nennen kann. nichts weiter suchend. [...] Keine Gesellschaften. kein sich nach Ruhm. nach Bedeutung Drängen. [...] Aber in meinen Arbeiten fühle ich mich. ohne alle außerordentliche Lebhaftigkeit. ohne alles, was etwa vorüberrauchen [!] könnte. wohler. konzentrierter, mehr auf den rechten Punkt gelenkt. und davon gar nicht wieder abgezogen. als in Leipzig. Ja. ich fühle wohl. daß ich für Dinge, die gerade Arbeiten meiner eigenen Wahl sind, hier mehr leisten werde als in Leipzig. [...] An meinen Collegien habe ich wirklich Freude und denke sie zu behalten, wenn gleich nicht alle Tage sich gleich sind. noch sein werden. Der Wunsch, mir mit ihnen Ehre einzulegen. worunter auch begriffen ist. wirklich etwas mit ibnen zu bewirken, ist der entschiedenste. den ich habe."

Weiter konnte er mitteilen, dass seine sehr gute äußere Situation es ermöglichen wird, seine Schulden, die er auf seiner mehrjährigen Reise gemacht hat, vollständig tilgen zu können, zumal er voraussichtlich seine eigene Mineralsammlung verkaufen kann, ,die in meinen Augen, seit ich hier das Kabinett ansehe und auf billige Art vergleiche, beträchtlich im Werte gestiegen ist." 69 Abschließend schreibt er: „Ich wäre ein Tor gewesen, wenn ich in Leipzig geblieben wäre."

Bei Werner meldet er sich erst ein halbes Jahr nach seinem Dienstantritt mit einem Brief am 10. 4. 1811 (SBAF-4). Darin heißt es unter anderem:

..Im Bewußtsein dessen, was ich seit dem entscheidenden letzten Monat September gegen Sie unterlassen habe. sollte ich vor allen Dingen wohl fragen. ob Sie mir nicht vielleicht zürnen, nicht sowohl, daß ich gegen Ihren gütigen und mit so vielem Wohlwollen mir gegebenen Rat meinen Entschluß damals wirklich gefaßt. mehr noch. daß ich gar nicht unmittelbar schrifflichen Abschied von Ihnen genommen und da 3 ich Ihnen von hier aus noch gar keine Nachricht von mir gegeben habe. Indeß ich glaube Ihrer unveränderlichen Güte so sicher zu sein, daß Sie auch wegen dieser Entschuldigungen nachsichtig mit mir sind und lieber Nachrichten von der Gegenwart mit wohl wollender Teilnahme aufnehmen. [...] Ich habe noch keine Stunde es bereut. hierher gegangen zu sein; und es scheint mir auch nicht leicht. daß dies sich ändern sollte. Ich befinde mich. ohne mich im vorzüglichen Sime glücklich zu fühlen, wahrhaft zufrieden und dabei denke ich, soll es bleiben. [...] Meine Lage ist mir angemessen. in einem doch vorzüglicheren Grade als in Leipzig. Die persönlichen Verhältnisse, in denen ich stehe, sind durchaus gut. An dem ferneren Wachsen der Universität und der Befestigung eines recht guten Geistes in ihr. den man wohl von ihr rühmen darf. ist billigerweise nicht zu zweifeln. Und von der Zukunft, die wir alle mit offenbarer oder verdeckterer Unsicherheit entgegensehen. fürchte ich keine solchen Schreck- nisse, die die neue Pflanzung gänzlich wieder zu Grunde richten sollten."

Der letzte Satz dieses Briefes, der sich bewahrheitete, soll die Überleitung zu dem vorgesehenen vierten Teil der Artikelserie bilden, der für das Wirken von C. S. Weiss in Berlin als Professor der Mineralogie und als Direktor des Mineralogischen Museums der Berliner Universität vorgesehen ist.

\section{Schriftenverzeichnis}

\section{Archivalien}

Vorbemerkung: In allen Zitaten aus historischen Quellen wurden Orthographie und Interpunktion unter Wahrung des Wortlautes behutsam modernisiert und Abkürzungen aufgelöst. - Die Nummerierung der Archivalien schließt sich an den 1. und den 2. Teil dieser Artikelserie an.

Geheimes Staatsarchiv Preußischer Kulturbesitz Berlin-Dahlem.

GSTAB-13 = 1 - Rep.76, Va, Sect. 2, Tit. 1, Nr. 2, vol. 3, Bl. $249,163.243$.

GSTAB-14 = $1-$ Rep.76, Va, Sect. 2, Tit. 1, Nr. 2, vol. 4, Bl. $236-237$.

Historische Handschriftensammlung des Museums für Naturkunde

HHMfN-1 = Bestand GfN. Tagebücher der Gesellschaft naturforschender Freunde.

HHMfN-3 = Bestand Mineralogisches Museum, Besucherbuch des Königlichen Mineralienkabinetts

HHMfN-4 = Bestand Paläontologisches Museum, Tagebücher von Leopold v. Buch.

Handschriftenabteilung der Universitätsbibliothek Bonn HUBB-1 = Autographensammlung, Manuskript Karsten

Schriftgutsammlung der Technischen Universität Bergakademie Freiberg

SBAF-3 = Handschriftlicher Werner-Nachlaß, Briefe an Werner, Briefe von $L$. v. Buch.

SBAF-4 = Handschriftlicher Werner-Nachlaß, Briefe an Werner. Briefe von C. S. Weiss.

SBAF-5 = Handschriftlicher Werner-Nachlaß, Briefe an Werner. Briefe von D. L. G. Karsten.

Handschriften-Abteilung der Staatsbibliothek Preußischer Kulturbesitz in Berlin

HASTB-3 = Nachlaß C. S. Weiss, Briefe an seine Geschwister.

HASTB $-4=$ Nachlaß C. S. Weiss, Brief an Carus.

HASTB $-5=$ Nachlaß C. S. Weiss, Brief an Oken.

\section{Literatur}

Bekkerhin, C. \& Kramp, C. 1793. Kristallographie des Mineralreichs. XL, 439 pp., Stahel, Wien.

Bergman, T. 1773. Variae crystallorum formae, a spatho ortae. - Nova Acta Regiae Societatis Scientiarum Upsaliensis. 1: $150-155$.

${ }^{69}$ Die private Sammlung von Weiss wurde nach Begutachtung durch H. Steffens (vgl. Anm. 62) für das Mineralogische Museum der Univ. Berlin angekauft (Hoppe 1982: 246). Vom Ministerium war festgelegt worden, die von Karsten begründete Tradition, dass der Leiter der Mineralogischen Sammlung privates Sammeln aufgibt, fortzusetzen. 
- 1780. De formis crystallorum, praesertim e spatho ortis. In Opuscula physica et chemica. Upsaliae, Vol. II: 1-25.

- 1782. Von der Figur der Crystalle, vornehmlich welche aus dem Spath entstehet. In Kleine Physische und Chymische Werke. 2. Band: 3-31, Garbe, Frankfurt a. M.

Bernhardi, J. J. 1809. Gedanken über Krystallogenie und Anordnung der Mineralien, nebst einigen Beilagen über die Krystallisation verschiedener Substanzen (als Verfolg der Darstellung einer neuen Methode, Krystalle zu beschreiben). - Journal für die Chemie, Physik und Mineralogie 8: $360-423$.

Biester, J. E. 1804. Nachricht von der Gründung der Philomathischen Gesellschaft in Berlin. - Neue Berlinische Monatsschrift 11: 231-235.

Böttiger, C. A. 1817. Worte, auf der Anhöhe der Landstraße nach Gorbitz gesprochen an Werners Sarge, in der 11ten Stunde der Nacht zwischen dem 2ten und 3ten July 1817. 16 pp., Arnold, Dresden.

Brochant [de Villiers], A. J. M. 1801/3. Traité élémentaire de minéralogie suivant les principes du Professeur Werner, conseiller des mines de Saxe. 3 Bde., Villier, Paris.

Buch, L. v. 1794. Beobachtungen über den Kreuzstein. Leipzig. (Auch in Ewald, J. u. a. 1867/85, Bd. 1: 24-35).

- 1799. Mémoire sur la formation de la leucite. - Journal de Physique, Paris, 49: 262-270. (Auch in Ewald, J. u. a. 1867/85, Bd. 1: 109-118).

- 1800. [Brief an den Herausgeber vom 3.12.1799]. - Jahrbücher der Berg- und Hüttenkunde [Hrsg. v. Moll], 4: 419-424. (Auch in Ewald, J. u. a. 1867/85, Bd. 1: 121-124).

- 1802/3. Observations sur les volcans d'Auvergne. - Journal des Mines 13: 249-256, Paris. (Nicht in Ewald, J. u. a. 1867/85).

- 1818. Lobrede auf [D.L.G.] Karsten. - Abhandlungen der Königl. Akademie der Wissenschaften, Berlin, 7-23. [Rede gehalten am 3.7.1814].

Buffon, G. L. L. de 1749/88: Histoire naturelle, générale et particulière. 36 Bände, Paris.

Carnot, L. N. M. 1803/5. Principes fondamentaux de l'équilibre et du mouvement. Paris. - Grundsätze der Mechanik vom Gleichgewicht und der Bewegung. Übersetzung von C. S. Weiss. Leipzig.

Chenevix, R. 1804. Sur un mémoire du Dr. Christian-Samuel Weiss, imprimé dans le minéralogie de M. Haüy, traduite en allemand par Dietrich-Ludwig-Gustave Karsten, conseiller des mines de S.M. Prussienne, etc. avec quelques remarques sur cette traduction. - Annales de Chimie 52 307-339, Paris.

- 1805. Bemerkungen, veranlaßt durch einen Aufsatz des Dr. Christian Samuel Weiss, der in der deutschen Übersetzung von Hauy's Mineralogie durch D. L. G. Karsten, kön. preuß. Geh. Oberbergrath, abgedruckt ist. - Annalen der Physik (Hrsg. L. W. Gilbert) 20: 455-484, Leipzig.

- 1807. Auszug aus einem Briefe von Herrn Chenevix, an den Prof. Gilbert. - Annalen der Physik (Hrsg. L. W. Gilbert) 25: 333-339, Leipzig.

- 1808. Réflexions sur quelques méthodes minéralogiques. - Annales de Chimie 65: 5-43, 113-160, 225-276, Paris.

Daubuisson, J.-F. 1802. Lettre à J.-C. Delamétherie sur quelques points de minéralogie. - Journal de physique, de chimie et d'histoire naturelle 54: Floreal an 10, 333-344.

Emmerling, L. A. 1793/9. Lehrbuch der Mineralogie. 3 Teile. Heyer, Gießen. (2.Aufl 1799/1802).

Estner, A. 1794/9. Versuch einer Mineralogie für Anfänger und Liebhaber. Nach Werners Methode. 4 Bände. Schmidt und Oehler, Wien.

Ewald, J. 1867. Leopold von Buch's Leben und Wirken bis zum Jahre 1806. In Ewald, J. u. a. 1867/85, Bd. 1, V-XLVII, Reimer, Berlin.

Ewald, J., Roth, J. \& Eck, H. (Hrsg.). 1867/85. Leopold von Buch's Gesammelte Schriften. Bd. 1, 1867, LII, 739 pp; Bd. 2, 1870, VIII, 783 pp.; Bd. 3, 1877, VIII, 714 pp.; Bd. 4, 2 Hälften, 1885, XII, 1058 pp., Reimer, Berlin.
Fabian, E. 1986. Die Entdeckung der Kristalle. Der historische Weg der Kristallforschung zur Wissenschaft. 196 pp, Deutscher Verlag für Grundstoffindustrie, Leipzig.

Fischer, E. 1962. C. S. Weiss und seine Bedeutung für die Entwicklung der Kristallographie. - Wissenschaftliche Zeitschrift der Humboldt-Universität Berlin, Mathematisch-Naturwissenschaftliche Reihe 11: 249-255.

- 1963. Christian Samuel Weiss und die zeitgenössische Philosophie (Fichte, Schelling). - Forschungen und Fortschritte 13: 141-143.

Fischer, W. 1936. Abraham Gottlob Werner in Darstellungen der bildenden Künste. - Mitteilungen des Roland 21: $61-68$.

Frisch, S. G. 1825. Abraham Gottlob Werners Lebensbeschreibung, nebst 2 Abhandlungen über Werners Verdienste um Oryktognosie und Geologie von C. S. Weiss. XVIII, 275 pp., Brockhaus, Leipzig.

Groth, P. 1925. Zur Geschichte der Krystallkunde. - Die Naturwissenschaften 13: 61-66.

- 1926. Entwicklungsgeschichte der mineralogischen Wissenschaften. VI, 261 pp., Springer, Berlin.

Haüy, R. J. 1783. Essai d'une théorie sur la structure des crystaux, appliquée à plusieurs genres de substances crystallisées. VIII, 236 pp., Gogue et Née de la Rochelle, Paris.

- 1801. Traité de minéralogie. 4 vol. et atlas.,T.1 LVI, 494 pp., T. 2 IV, 617 pp., T. 3 IV, 588 pp., T. 4 VI, 592 pp., T. 5 VIII, 10 pp., LXXXVI pl., Louis, Paris.

- 1804/1806/1810. Lehrbuch der Mineralogie (Hrsg. D. L. G. Karsten). 4 Textbände und Tafelband, Bd. 1, XX, 611 pp. (1804), Bd. 2, XX, 723 pp. (1804), Bd. 3 XXXII. 686 (1806), Bd.4, VIII, 734 (1810), Bd. 5, Tafeln (1810), Reclam, Paris und Leipzig. (Übersetzer waren C. S. Weiss und K. J. B. Karsten zu gleichen Teilen, C. S. Weiss war Mitherausgeber ab Bd.3).

- 1804/5. Traité élémentaire de physique. Paris. - Übersetzung durch C. S. Weiss: Handbuch der Physik für den Elementarunterricht. 2 Bde. (Erster Band auch unter dem Titel: Anfangsgründe der Physik). Leipzig.

- 1809. Tableau comparatif des résultats de la cristallographie et de l'analyse chimique, relativement à la classification des minéraux. LVII, 312 pp., Courcier, Paris.

Hermann, A. 1977. Schelling und die Naturwissenschaften. Technikgeschichte 44: 47-53.

Herwig, W. (Hrsg.) 1965. Goethes Gespräche. Eine Sammlung zeitgenössischer Berichte aus seinem Umgang auf Grund der Ausgabe und des Nachlasses von F. Frh. v. Biedermann. Bd.1. Artemis, Zürich und Stuttgart.

Hoffmann, C. A. S. 1804. Hrn. Daubuisson's Schreiben an Hrn. Delametherie über verschiedene Punkte der Mineralogie. - Neues Bergmännisches Journal 4 (1816): $137-162$.

Hoppe, G. 1982. Christian Samuel Weiss und das Berliner Mineralogische Museum. - Wissenschaftliche Zeitschrift der Humboldt-Universität Berlin, Mathematisch-naturwissenschaftliche Reihe 31: 245-254.

- 1987. Das Königliche Mineralienkabinett in Berlin, Vorläufer des Mineralogischen Museums der Berliner Universität. - Neue Museumskunde 30: 295-307.

- 1994. Die Entwicklung der Ansichten Alexander von Humboldts über den Vulkanismus und die Meteorite. In Studia Fribergensia. A.-v.-Humboldt-Kolloquium Freiberg 1991. Beiträge zur A.-v.-Humboldt-Forschung, Berlin 18: 93-113.

- 1998. Zur Geschichte der Geowissenschaften im Museum für Naturkunde zu Berlin. Teil 1. Aus der Vorgeschichte bis zur Gründung der Berliner Bergakademie im Jahre 1770. - Mitteilungen aus dem Museum für Naturkunde der Humboldt-Universität in Berlin, Geowissenschaftliche Reihe 1: 5-19.

- 1999a. Zur Geschichte der Geowissenschaften im Museum für Naturkunde zu Berlin. Teil 2. Von der Gründung der Bergakademie zur Gründung der Universität 1770-1810. - Mitteilungen aus dem Museum für Natur- 
kunde der Humboldt-Universität in Berlin. Geowissenschaftliche Rcihe 2: 3-24.

- 1999b, Die Tagebucher Leopold von Buchs. Chronologische Ubersicht. - Geohistorische Blätter. Zeitschrift des Vereins Berlin-Brandenburgische Geologie-Historiker .Leopold von Buch" 2: 107-115.

- 1999c. Leopold von Buchs Verhältnis zu Abraham Gottlob Werner. Mit Regesten der Briefe v. Buchs an Werner und Auszügen aus dem Tagebuch $v$. Buchs des Jahres 1804. - Symposium ..A. G. Werner und seine Zeit". Kurzfassung im Tagungsband erschienen.

Kant. I. 1755. Allgemeine Naturgeschichte und Theorie des Himmels oder Versuch ron der Verfassung und dem mechanischen Ursprunge des ganzen Weltgebäudes nach Newtonschen Grundsätzen abgehandelt. Königsberg. Leipzig,

- 1786. Metaphysische Anfangsgründe der Naturwissenschaft. Riga.

Karsten. D. L. G. 1786. Anmerkungen zur Übersetzung der Abhandlung des Herrn Romé de l'Isle. Von den äußerlichen Kennzeichen der Fossilien. - Magazin der Bergbaukunde 2: $43-68$.

- 1791/1792. Tabellarische Übersicht der mineralogisch-einfachen Fossilien zum Behufe seiner Vorlesungen. VIII: 27 pp. Hofdruckerei. Berlin. (2. Aufl.: Rottmann. Berlin. XII: 35 pp.).

- 1800/1808. Mineralogische Tabellen mit Rücksicht aut die neuesten Entdeckungen. VIII. 79 pp.. Rottmann. Berlin. (2. Auflage: XIV: 104 pp.).

Karsten. D. L. G. (Hrsg.) 1804/1806/1810 siehe Haüy. R. J. $1804 / 1806 / 1810$.

Karsten. [D. L. G.] 1805. Antwort an Herrn Chenevix. in Betreff seiner Bemerkungen, veranlasst durch einen Aufsatz des Dr. Weiss in der deutschen Übersetzung von Hauys Mineralogie. - Annalen der Physik (Hrsg. L. W. Gilbert) 20: $497-503$.

Karsten. G. 1855. Umrisse zu Carl Johann Bernhard Karsten's Leben und Wirken. - Archiv für Mineralogie. Geognosie, Berghau und Hüttenkunde 26: 195-372.

Kreußler. H. G. 1810. Beschreibung der Feierlichkeiten am Jubelfeste der Universität Leipzig d. 4. Dec. 1809. nebst kurzen Lebensbeschreibungen der Herren Professoren. VIII. 78 pp., Solbrig. Leipzig.

Lenz. M. 1910. Geschichte der königlichen Friedrich-Wilhelms-Universität zu Berlin. Bd. 1. Gründung und Ausbau. XV. 644 pp.. Bd. 2. 1. Ministerium Altenstein. IX. 514 pp.. Bd. 2. 2. Auf dem Wege zur deutschen Einheit im Neuen Reich. XII. 512 pp.. Bd. 3. Wissenschaftliche Anstalten. Spruchkollegium. Statistik. VIII. 536 pp.. Bd. 4. Urkunden. Akten. Briefe. XII. 602 pp. Verlag des Waisenhauses. Halle.

Leonhard. K. C. v. 1817. Zu Werners Andenken. gesprochen in der Versammlung der Königlichen Akademic der Wissenschaften zu München am 25. Oktober 1817. - 32 pp. Hermann, Frankfurt a. M.

Linné. C. v. 1768. Systema naturae. 12. ed.. tom. III. Holmiae. Mathé. G. 1985. Karl Ernst Adolf von Hoff (1771 bis 1837) - In Leben und Wirken deutscher Geologen im 18. und 19. Jahrhundert. (Hrsg. H. Prescher). Dt. Verl. f. Grundstoffindustrie. Leipzig. 118-139.

Oken. L. 1808/11. Lehrbuch der Naturphilosophie. 3 Bände. Jena.

Örsted. H. C. 1920. Correspondance de H. C. Örsted avec divers savants. Publiée par M. C. Harding. Tome 1. X: 367 pp. Aschehoug. Copenhague.

Paufler. P. 1981. C. S. Weiss in seiner Leipziger Periode. Wissenschaftliche Zeitschrift der Karl-Marx-Universität Leipzig. Mathematisch-Naturwissenschaftliche Reihe 30: $428-433$.

Romé de MIsle. J. B. L. 1772. Essai de cristallographie ou description des figures géométriques. propres à différens corps du règne minéral connus vulgairement sous le nom des crystaux. XXXII. 429 pp.. Didot jeune. Paris.
- 1783. Cristallographie, ou description des formes propres à tous les corps du règne minéral, dans l'état de combinaison saline, pierreuse ou métallique. Seconde édition. 4 Bde. I: XI. 625 pp. II: 659 pp., III: 611 pp., IV: Tafelband XVI. 80 pp.. Imprimerie de Monsieur, Paris.

1784. Des caractères extérieures des minéraux, ou reponse à cettc question: Existe-t-il dans les substances du règne minéral des caractères qu'on puisse regarder comme spécifiques: et au cas qu'il en existe, quels sont ces caractères?. 83 pp., Paris. - Übersetzung ins Deutsche von D. L. G. Karsten unter dem Titel: „Von den äußerlichen Kennzeichen der Fossilien. Oder Antwort auf die Frage: Giebt es an den Körpcrn des Mineralreichs Kennzeichen. die man als gewiss an sehen kann; und welches sind (im Falle. dass es welche giebt) diese Kennzeichen." - Magazin der Bergbaukunde 2 (1786): 1-42.

Schelling. F. W. J. 1797. Ideen zu einer Philosophie der Natur.

- 1799. Erster Entwurf cines Systems der Naturphilosophie. Zum Behufe seiner Vorlesungen. Jena und Leipzig.

Schmidt. P. 1999. Bergrath Abraham Gottlob Werner (1749-1817). Ritter des Königl. Sächs. Civil Verdienst Ordens. Gelehrter von Weltbedeutung, 1. Fassung. Nachrichtenblatt zur Geschichte der Geowissenschaften. 7/8 (für 1997/98): 133-146.

Schuster. J. 1922. Aus unveröffentlichten Dokumenten zur Geschichte der Mineralogie. Geologie und Paläontologie. Historische Miniaturen. I. Christian Samuel Weiss und die Naturphilosophic. II. Christian Samuel Weiss' kristallographisches System und René Just Haüy. Mit einem unveröffentl. Brief von Oken. In Degering, H., Christ, K. \& Schuster, J.: Aus der Handschriftenabteilung der Preußischen Staatsbibliothek. Breslauer, Berlin: 87-103.

Schuster, J. \& Bloch, R. 1924. Leopold von Buch's Bricfe an D. L. G. Karsten. Zu seinem 150. Geburtstage. 32 pp., Junk. Berlin.

Steiger, R, 1986. Goethes Leben von Tag zu Tag. Bd. IV (1799-1806). Artemis, Zürich und München.

Struve. H. 1799. Principes de minéralogie, ou Exposition succincte des caractères extérieurs des fossiles, d'après les leçons du professeur Werner, augmentées d'addition manuscrites fournis par cet auteur par J. P. van BerchemBerthout et H. Struve. VII, 179 pp., Reynier, Paris.

Townsend. J. 1791. A journey through Spain in the years 1786 and 1787. with particular attention to agriculture, manufactures. commerce. population, taxes, and revenue of that country, and remarks in passing through a past of France. 3 vol. Dilly. London.

Wad. G. 1798. Tabulae synopticae terminorum systematis oryctognostici Werneriani. latine. danice et germanice. 27 pp. Brummer. Hafniae.

Wagenbreth. O. 1955. Abraham Gottlob Werner und der Höhepunkt des Neptunistenstreites um 1790. - Freiberger Forschungshefte D 11: 183-241.

-- 1957. Werner-Schüler als Geologen und Bergleute und ihre Bedeutung für die Geologie und den Bergbau des 19. Jahrhunderts. - Freiberger Forschungshefte C 223: $163-178$.

Weiss. [C.] E. 1880. Gedenkworte am Tage der Feier des hundertjährigen Geburtstages von Christian Samuel Weiss. den 3. März 1880. - Zeitschrift der deutschen geologischen Gesellschaft 32: VI-XXI.

Weiss. C. S. 1801 a. De notionibus rigidi et fluidi accurate definiendis dissertatio physica. 57 pp., Tauchnitz, Lipsiae. $1801 \mathrm{~b}$. Über die Anwendbarkeit und Nützlichkeit der Hagelableiter. - Neue Schriften der Gesellschaft naturforschender Freunde zu Berlin 3: 35-94.

- 1804. Dynamische Ansicht der Krystallisation. In Haüy, R. J.: Lehrbuch der Mineralogie (Hrsg. D. L. G. Karsten). Bd. 1: $365-389$.

- 1805. Antwort auf einen Angriff des Herm Chenevix. Neues allgemeines Journal der Chemie (Hrsg. A. F. Gehlen) $5: 335-342$. 
- 1807. Notice sur un nouvel instrument, ... extrait d'une lettre écrite par Mr. Ritter à Mr. Weiss. - Bibliothèque Britannique, Genève 35: 80-96.

- 1809. De indagando formarum crystallinarum charactere geometrico principali dissertatio. - De charactere geometrico principali formarum crystallinarum octaedricarum pyramidibus rectis basi rectangula oblonga commentatio. 49 pp., Tauchnitz, Lipsiae.

- 1811. Dissertatio de indagando formarum cristallinarum caractere geometrico principali - ou: Mémoire sur la détermination du caractère géométrique principal des formes cristallines. - Traduit par M. Brochant de Villiers. Journal des Mines 29: 349-391, 401-444.
Werner, A. G. 1774. Von den äußerlichen Kennzeichen der Foßilien. 304 pp., Crusius, Leipzig.

- 1791/1792. Ausführliches und sistematisches Verzcichnis des Mineralien-Kabinets des weiland kurfürstlich sächsischen Berghauptmans Herrn Eugen Pabst von Ohain. 2 Bde. I: XXXII, 368 pp., II: XXXX, 286 pp., Craz. Freiberg und Annaberg.

Werner/Carozzi 1962. Werner, A. G.: On the external characters of minerals. Translated by A. V. Carozzi. XXXI + 118 pp., University of Illinois Press, Urbana.

Widenmann, J. F. W. 1794. Handbuch des oryktognostischen Theils der Mineralogie. XIV, 1040 pp., Register 15 unnum. pp., Crusius, Leipzig. 